\title{
Decoding the Human Immunoglobulin G-Glycan Repertoire Reveals a Spectrum of Fc-Receptor- and Complement- Mediated-Effector Activities
}

OPEN ACCESS

Edited by:

José Mordoh,

Fundación Instituto Leloir, Argentina

Reviewed by:

Raffael Nachbagauer, Icahn School of Medicine at Mount

Sinai, United States

Johannes S. Gach, University of California, Irvine, United States

*Correspondence:

Gestur Vidarsson g.vidarsson@sanquin.nı

Specialty section: This article was submitted to Vaccines and Molecular Therapeutics,

a section of the journal

Frontiers in Immunology

Received: 08 May 2017 Accepted: 10 July 2017 Published: 02 August 2017

Citation:

Dekkers G, Treffers L, Plomp R, Bentlage AEH, de Boer M, Koeleman CAM, LissenbergThunnissen SN, Visser R, Brouwer M, Mok JY, Matlung $H$, van den Berg TK, van Esch WJE, Kuijpers TW,

Wouters D, Rispens T, Wuhrer M and Vidarsson G (2017) Decoding the Human Immunoglobulin G-Glycan Repertoire Reveals a Spectrum of Fc-Receptor- and ComplementMediated-Effector Activities.

Front. Immunol. 8:877. doi: 10.3389/fimmu.2017.00877

\begin{abstract}
Gillian Dekkers', Louise Treffers², Rosina Plomp³, Arthur E. H. Bentlage', Marcella de Boer ${ }^{1}$, Carolien A. M. Koeleman ${ }^{3}$, Suzanne N. Lissenberg-Thunnissen', Remco Visser ${ }^{1}$, Mieke Brouwer ${ }^{4}$, Juk Yee Mok ${ }^{5}$, Hanke Matlung ${ }^{2}$, Timo K. van den Berg ${ }^{2}$, Wim J. E. van Esch ${ }^{5}$, Taco W. Kuijpers ${ }^{2}$, Diana Wouters ${ }^{4}$, Theo Rispens ${ }^{4}$, Manfred Wuhrer ${ }^{3}$ and Gestur Vidarsson ${ }^{1 *}$

\footnotetext{
'Sanquin Research and Landsteiner Laboratory, Department Experimental Immunohematology, Academic Medical Centre, University of Amsterdam, Amsterdam, Netherlands, ${ }^{2}$ Sanquin Research and Landsteiner Laboratory, Department Blood Cell Research, Academic Medical Centre, University of Amsterdam, Amsterdam, Netherlands, ${ }^{3}$ Center for Proteomics and Metabolomics, Leiden University Medical Center, Leiden, Netherlands, ${ }^{4}$ Sanquin Research and Landsteiner Laboratory, Department Immunopathology, Academic Medical Centre, University of Amsterdam, Amsterdam, Netherlands, ${ }^{5}$ Sanquin Reagents, Amsterdam, Netherlands
}

Glycosylation of the immunoglobulin G (IgG)-Fc tail is required for binding to Fc-gamma receptors (FcyRs) and complement-component C1q. A variety of IgG1-glycoforms is detected in human sera. Several groups have found global or antigen-specific skewing of IgG glycosylation, for example in autoimmune diseases, viral infections, and alloimmune reactions. The IgG glycoprofiles seem to correlate with disease outcome. Additionally, IgGglycan composition contributes significantly to lg-based therapies, as for example IVlg in autoimmune diseases and therapeutic antibodies for cancer treatment. The effect of the different glycan modifications, especially of fucosylation, has been studied before. However, the contribution of the 20 individual lgG glycoforms, in which the combined effect of all 4 modifications, to the lgG function has never been investigated. Here, we combined six glyco-engineering methods to generate all 20 major human IgG1-glycoforms and screened their functional capacity for FcyR and complement activity. Bisection had no effect on FcyR or C1q-binding, and sialylation had no- or little effect on FcyR binding. We confirmed that hypo-fucosylation of IgG1 increased binding to FcyRllla and FcyRlllb by 17 -fold, but in addition we showed that this effect could be further increased to $~ 40$-fold for FcyRllla upon simultaneous hypo-fucosylation and hyper-galactosylation, resulting in enhanced NK cellmediated antibody-dependent cellular cytotoxicity. Moreover, elevated galactosylation and sialylation significantly increased (independent of fucosylation) C1q-binding, downstream complement deposition, and cytotoxicity. In conclusion, fucosylation and galactosylation are primary mediators of functional changes in IgG for FcyR- and complement-mediated effector functions, respectively, with galactose having an auxiliary role for Fc $\gamma \mathrm{R}$ III-mediated functions. This knowledge could be used not only for glycan profiling of clinically important (antigen-specific) lgG but also to optimize therapeutic antibody applications.

Keywords: immunoglobulin G glycosylation, Fc gamma receptor, antibody-dependent cellular cytotoxicity, complement, antibody effector functions 


\section{INTRODUCTION}

The importance of the biological properties of antibodies to specifically engage a target of choice and activate complement and Fc gamma receptors $(\mathrm{F} c \gamma \mathrm{R})$ on immune cells (1) is currently more and more recognized in modern medicine. For cancer therapies using tumor targeting antibodies, strong effector functions are preferred (2). Various strategies have been exploited to generate antibodies that are more effective than wild-type human IgG1 isotype (3). These include fusions with toxic molecules and incorporations of mutations that enhance affinities to Fc $\gamma$ R. Possible drawback of such modifications is the introduction of foreign immunogenic epitopes that can result in anti-drug antibodies that may neutralize the drug. This can be circumvented by using non-immunogenic natural variations, found in all individuals. The prototypic variation of this kind are glyco-engineered IgG1 antibodies without fucose with elevated FcyRIIIa affinities $(4,5)$, which have already found its way to therapeutic antibodies on the market (6).

This fucose residue is part of a conserved glycan on asparagine 297 in the Fc domain of immunoglobulin G (IgG). This glycan is important for the quaternary structure of the Fc part, since its removal abrogates binding of $\mathrm{Fc} \gamma \mathrm{R}$ and $\mathrm{Clq}$ and hence the antibody's effector functions (7-9). In addition to affecting the Fc structure and thereby recognition by these effector molecules, the Fc-glycan also affects binding to FcyRIIIa and FcyRIIIb through a glycan-glycan interaction $(10,11)$. This is because of a unique glycan found in human FcyRIIIa and Fc $\gamma$ RIIIb at position 162 that interacts directly with the Fc-glycan within the IgG-Fc cavity (11).

The N297 glycan is a bi-antennary complex glycan composed of a constant part with a core consisting of $\mathrm{N}$-acetylglycosamines and mannoses and can be found in human serum with variable levels of core fucose, bisecting $\mathrm{N}$-acetylglycosamine, galactose, and terminal sialic acids (12). The N-glycans of total serum/ plasma IgG consists on average of high fucose levels (95\%), low bisection (15\%), intermediate levels of galactose (45\%), and low sialic acid (10\%) (12). The variable assembly of the glycans amounts to at least 20 different glycoforms (a term used here to describe one unique glycan combination) for each IgG subclass being found in serum, with $\sim 8$ of them accounting for $90 \%$ of the total abundance (12). The composition of total IgG glycosylation can change upon certain settings, where galactosylation and sialylation increase with pregnancy $(12,13)$. Changes in total IgG are also observed in various clinical settings, with a low level of galactosylation and sialylation associated both with increasing age and autoimmune diseases (12-15).

We and others have shown that IgG-Fc glycosylation changes of antigen-specific IgG can occur that correlate with disease outcome (16-20). This includes both auto- and alloimmune disorders, including fetal neonatal immune thrombocytopenia (FNAIT), immune thrombocytopenia, and hemolytic disease of the fetus and newborn (HDFN) $(16-18,21,22)$. In particular, we have found that immune responses against red blood cell (RBC) and platelets, either transfused or during pregnancy, can be characterized with extremely low fucose (down to 10\%), high galactose (up to $80 \%$ ), and elevated sialylation levels $(\sim 35 \%)$.
Notably, lowered Fc-fucosylation $(17,21)$, but also elevated Fc-galactosylation (18), seemed to correlate with elevated blood cell destruction, severity of anemia or bleeding for RBCs and platelets, respectively. Whereas the increased pathogenicity associated with lowered fucosylation could be explained by the resulting elevated FcyRIIIa and/or FcyRIIIb activity $(17,23)$, the functional reasons-if any-behind the association with elevated galactosylation remained enigmatic.

The effect of Fc-bisection and -sialylation on human FcyR binding, if any, has been studied in even less detail, although binding to the human FcyRIIIa does not seem to be affected by sialylation (24). Whether these glycan changes influence binding to C1q, and subsequent complement activation, has not been studied in detail $(25,26)$. A drawback of all these studies is that the impact of the glycan changes was studied changing only individual end groups, without investigating the possibility that the context of the other glycan changes may have an effect on the antibody effector functions.

The complexity of the glycan-assembly makes investigation into their biological relevance extremely difficult. Previous attempts have generated a handful of defined glycoforms and tested binding to part of the Fc $\gamma$ R-repertoire, but a systematic analysis for all possible glycan changes and effector mediators, Fc $\gamma$ Rs and complement, has never been achieved (24, 26-30). This information could provide the insight in working mechanisms of IgG-based treatments and allow meaningful clinical evaluation of the activity of potentially pathological antibodies such as in FNAIT and HDFN. We have, therefore, developed a set of glyco-engineering tools which specifically alter one of the N-glycan end groups (31) and in the present study we combined these tool to create 20 different natural glycoforms to systematically investigate them with regard to Fc $\gamma \mathrm{R}$ binding, antibody-dependent cellular cytotoxicity (ADCC), complement binding, and activation.

\section{MATERIALS AND METHODS}

\section{Human Samples}

Peripheral blood from anonymous, healthy volunteers was obtained with informed, written consent in accordance with Dutch regulations. This study was approved by the Sanquin Ethical Advisory Board in accordance with the Declaration of Helsinki.

Heparinized blood samples were used for isolation of peripheral blood mononuclear cells (PBMCs) or RBCs. NK cell isolation was only performed with blood from well-genotyped donors who do not express FcyRIIc (32) to exclude any possible effects of this receptor. Serum was obtained by allowing blood without anticoagulants to coagulate for $1 \mathrm{~h}$ at room temperature (RT) and collecting the supernatant after centrifugation at $950 \times g$ for $10 \mathrm{~min}$. Serum of three different volunteers was combined to create a serum pool.

\section{Strains and Reagents}

Escherichia coli strain DH5 $\alpha$ was used for recombinant DNA work. Restriction endonucleases, DNA modification enzymes were obtained from Thermo Fisher Scientific (Waltham, MA, 
USA). Oligonucleotides were obtained from Geneart (Thermo Fisher Scientific) or Integrated DNA Technologies (Coralville, IA, USA).

\section{IgG1 Expression Vector Constructs}

Variable (V) genes for anti-human RhD (anti-D clone 19A10) heavy and light chain were sequenced from a single human $\mathrm{B}$ cell from a hyper immunized donor (33). A single-gene vector containing anti-D or anti-TNP IgG1 heavy- and kappa lightchain-encoding sequences were cloned as described previously by Kruijsen et al. (34) into a pEE14.4 (Lonza, Basel, Switzerland) expression vector. For both anti-TNP and anti-D IgG, a single expression vector was generated. In brief, the codon-optimized $\mathrm{V}$ gene for both heavy and light chain, including $5^{\prime}$-HindIII and $3^{\prime}$-NheI or $5^{\prime}$-HindIII and $3^{\prime}$-XhoI restriction sites respectively, Kozak sequence, and HAVT20-leader sequence, were designed and ordered from Geneart (Thermo Fisher Scientific). The HindIII-NheI or HindIII-XhoI fragments for the codon-optimized heavy or light chain were ligated into $\gamma$ or $\kappa$ constant region flanking $3^{\prime}$-EcoRI restriction site, respectively. The HindIII-EcoRI fragment for the codon-optimized light chain was ligated into pEE14.4 (Lonza), and the HindIII-EcoRI fragment for the heavy chain was ligated into pEE6.4 (Lonza). A single-gene vector encoding IgG1 was subsequently generated by ligation of the BamHI-NotI fragment from pEE6.4 (including a cytomegalovirus promoter), IgG1 heavy chain, and poly (A) into the light-chain-encoding pEE14.4 vector.

\section{IgG1 Production and Glyco-Engineering}

IgG1 production in human embryonic kidney (HEK) F cells and purification using protein A affinity chromatography was performed as described previously by Kruijssen et al. (34) Glyco-engineering of IgG1 was optimized as described by Dekkers et al. (31) In short, to decrease either fucosylation or galactosylation, $0.4 \mathrm{mM}$ 2-deoxy-2-fluoro-L-fucose (2FF) (Carbosynth, Berkshire, United Kingdom) or $1 \mathrm{mM}$ 2-deoxy2-fluoro-D-galactose (2FG) (Carbosynth), respectively, was added to the cell suspension $4 \mathrm{~h}$ post transfection. To increase bisecting GlcNAc, 1\% pEE6.4 + GNTIII encoding mannosyl (beta-1,4-)-glycoprotein beta-1,4- $\mathrm{N}$-acetylglucosaminyltransferase (GNTIII) enzyme was co-transfected with 99\% IgG1-к $\mathrm{HC}+\mathrm{LC}$ vector. To increase galactose, $1 \%$ pEE6.4 + B4GALT1 encoding $\beta$-1,4-galactosyltransferase 1 (B4GALT1) enzyme was co-transfected with $99 \%$ IgG1 vector and $5 \mathrm{mM}$ D-galactose (Sigma Aldrich, Saint Louis, MO, USA) was added to the cell suspension $1 \mathrm{~h}$ before transfection. To increase sialylation, the level of galactosylation must also be elevated as sialic acid is the terminal sugar group with galactose residues as substrate. Thus, $1 \%$ pEE6.4 + B4GALT1 and 2.5\% pEE14.4 + STGALT encoding $\beta$-galactoside alpha-2,6-sialyltransferase 1 (ST6GALT) were both co-transfected $96.5 \%$ IgG1 vector and $5 \mathrm{mM}$ D-galactose was added to the cell suspension $1 \mathrm{~h}$ before transfection. To further increase sialylation, in vitro sialylation (ivs) was performed on the purified in vivo sialylated IgG created using the previous method. Recombinant human $\alpha-2,6$-sialyltransferase (Roche, Basel, Switzerland) and cytidine-5'-monophospho- $N$ acetylneuraminic acid (CMP-NANA) (Roche) were incubated at $37^{\circ} \mathrm{C}$ for $24 \mathrm{~h}$ with purified IgG1 with already in vivo enhanced galactose and sialic acid (as described above), after incubation samples were re-purified with protein A, as described previously $(31,34)$.

\section{Mass Spectrometry Analysis}

Immunoglobulin G-Fc glycan composition of produced IgG1 was determined by mass spectrometry as described previously by Dekkers et al. (31) Trypsin-digested glycopeptide samples were analyzed by nanoLC-ESI-QTOF-MS. The separation was performed on an RSLCnano Ultimate 3000 system (Thermofisher, Breda, the Netherlands) with a gradient pump, loading pump and an autosampler. $250 \mathrm{nl}$ of sample was injected and washed on a Dionex Acclaim PepMap100 C18 trap column $(5 \mathrm{~mm} \times 300 \mu \mathrm{m}$ i.d.; Thermofisher) for $1 \mathrm{~min}$ with $0.1 \% \mathrm{TFA}$ at a flow rate of $25 \mu \mathrm{l} /$ min. The sample was then separated on an Ascentis Express C18 nanoLC analytic column $(50 \mathrm{~mm} \times 75 \mu \mathrm{m}$ i.d.; $2.7-\mu \mathrm{m}$ fused core particles; Supelco, Bellefonte, PA) with a flow rate of $0.9 \mu \mathrm{l} / \mathrm{min}$ using linear gradient as described in Ref (30). The resulting coelution of the different glycoforms of the IgG1-Fc glycosylation site warrants fair comparison by ensuring identical ionization conditions for the various glycopeptide species. The LC was coupled to the MS detector via a CaptiveSpray source with a NanoBooster (Bruker Daltonics, Bremen, Germany). The latter enriched the $\mathrm{N}_{2}$ flow $\left(3 \mathrm{l} / \mathrm{min}\right.$ ) with $\mathrm{CH}_{3} \mathrm{CN}$ (pressure $0.2 \mathrm{bar}$ ), resulting in increased sensitivity. The samples were ionized in positive ion mode at $1,100 \mathrm{~V}$. The Maxis Impact quadrupole-TOFMS (micrOTOF-Q, Bruker Daltonics) was used as detector. MS1 spectra were collected at a frequency of $1 \mathrm{~Hz}$ with a scan range of $m / z 550-1,800$. The mass spectrometric data were calibrated internally in DataAnalysis 4.0 (Bruker Daltonics) using a list of known IgG glycopeptide masses. MSConvert (Proteowizard 3.0) (35) was used to convert the data files to mzXML format, and an in-house alignment tool (36) was used to align the retention times of the data files. The highest intensity of selected peaks (within an $\mathrm{m} / z$ window of \pm 0.2 and within a time window of $\pm 15 \mathrm{~s}$ surrounding the retention time) was extracted using the in-house developed 3D Max Xtractor software tool. If above a signal:background ratio of 3 , the background-subtracted area of the first three isotopic peaks of each glycopeptide in both $2+$, $3+$, and $4+$ charge state were summed, and this summed value was then divided by the total summed value of all IgG1 glycopeptides to arrive at a percentage for each glycopeptide. From these percentages, we calculated several derived traits using the following formulas: fucosylation (H3N3F1 + H4N3F1 + H5N3 $\mathrm{F} 1+\mathrm{H} 6 \mathrm{~N} 3 \mathrm{~F} 1+\mathrm{G} 0 \mathrm{~F}+\mathrm{G} 1 \mathrm{~F}+\mathrm{G} 2 \mathrm{~F}+\mathrm{H} 6 \mathrm{~N} 4 \mathrm{~F} 1+\mathrm{G} 0 \mathrm{FN}+\mathrm{G} 1 \mathrm{~F}$ $\mathrm{N}+\mathrm{G} 2 \mathrm{FN}+\mathrm{H} 6 \mathrm{~N} 5 \mathrm{~F} 1+\mathrm{H} 4 \mathrm{~N} 3 \mathrm{~F} 1 \mathrm{~S} 1+\mathrm{H} 5 \mathrm{~N} 3 \mathrm{~F} 1 \mathrm{~S} 1+\mathrm{H} 6 \mathrm{~N} 3 \mathrm{~F} 1$ $\mathrm{S} 1+\mathrm{G} 1 \mathrm{FS}+\mathrm{G} 2 \mathrm{FS}+\mathrm{H} 6 \mathrm{~N} 4 \mathrm{~F} 1 \mathrm{~S} 1+\mathrm{G} 2 \mathrm{FS} 2+\mathrm{G} 1 \mathrm{FNS}+\mathrm{G} 2 \mathrm{FNS}$ + H6N5F1S1 + G2FNS2), bisection (H6N4F1 + G0FN + G1FN $+\mathrm{G} 2 \mathrm{FN}+\mathrm{H} 6 \mathrm{~N} 5 \mathrm{~F} 1+\mathrm{H} 6 \mathrm{~N} 4 \mathrm{~F} 1 \mathrm{~S} 1+\mathrm{G} 1 \mathrm{FNS}+\mathrm{G} 2 \mathrm{FNS}+\mathrm{H} 6 \mathrm{~N} 5$ $\mathrm{F} 1 \mathrm{~S} 1+\mathrm{G} 2 \mathrm{FNS} 2+\mathrm{H} 6 \mathrm{~N} 4+\mathrm{G} 0 \mathrm{~N}+\mathrm{G} 1 \mathrm{~N}+\mathrm{G} 2 \mathrm{~N}+\mathrm{H} 6 \mathrm{~N} 5+\mathrm{H}$ $6 \mathrm{~N} 4 \mathrm{~S} 1+\mathrm{G} 1 \mathrm{NS}+\mathrm{G} 2 \mathrm{NS}+\mathrm{H} 6 \mathrm{~N} 5 \mathrm{~S} 1+\mathrm{G} 2 \mathrm{NS} 2)$, galactosylation $[(\mathrm{H} 4 \mathrm{~N} 3 \mathrm{~F} 1+\mathrm{H} 5 \mathrm{~N} 3 \mathrm{~F} 1+\mathrm{G} 1 \mathrm{~F}+\mathrm{H} 6 \mathrm{~N} 4 \mathrm{~F} 1+\mathrm{G} 1 \mathrm{FN}+\mathrm{H} 6 \mathrm{~N} 5 \mathrm{~F} 1$ $+\mathrm{H} 4 \mathrm{~N} 3 \mathrm{~F} 1 \mathrm{~S} 1+\mathrm{H} 5 \mathrm{~N} 3 \mathrm{~F} 1 \mathrm{~S} 1+\mathrm{H} 6 \mathrm{~N} 3 \mathrm{~F} 1 \mathrm{~S} 1+\mathrm{G} 1 \mathrm{FS}+\mathrm{H} 6 \mathrm{~N} 4 \mathrm{~F} 1 \mathrm{~S}$ $1+\mathrm{G} 1 \mathrm{FNS}+\mathrm{H} 6 \mathrm{~N} 5 \mathrm{~F} 1 \mathrm{~S} 1+\mathrm{H} 4 \mathrm{~N} 3+\mathrm{H} 5 \mathrm{~N} 3+\mathrm{H} 6 \mathrm{~N} 3+\mathrm{G} 1+$ $\mathrm{H} 6 \mathrm{~N} 4+\mathrm{G} 1 \mathrm{~N}+\mathrm{H} 6 \mathrm{~N} 5+\mathrm{H} 4 \mathrm{~N} 3 \mathrm{~S} 1+\mathrm{H} 5 \mathrm{~N} 3 \mathrm{~S} 1+\mathrm{H} 6 \mathrm{~N} 3 \mathrm{~S} 1+\mathrm{G} 1$ $\mathrm{S}+\mathrm{H} 6 \mathrm{~N} 4 \mathrm{~S} 1+\mathrm{G} 1 \mathrm{NS}+\mathrm{H} 6 \mathrm{~N} 5 \mathrm{~S} 1)^{*} 0.5+\mathrm{G} 2 \mathrm{~F}+\mathrm{G} 2 \mathrm{FN}+\mathrm{G} 2$ 
$\mathrm{FS}+\mathrm{G} 2 \mathrm{FS} 2+\mathrm{G} 2 \mathrm{FNS}+\mathrm{G} 2 \mathrm{FNS} 2+\mathrm{G} 2+\mathrm{G} 2 \mathrm{~N}+\mathrm{G} 2 \mathrm{~S}+\mathrm{G} 2 \mathrm{~S} 2$ $+\mathrm{G} 2 \mathrm{NS}+\mathrm{G} 2 \mathrm{NS} 2]$, sialylation $[(\mathrm{H} 4 \mathrm{~N} 3 \mathrm{~F} 1 \mathrm{~S} 1+\mathrm{H} 5 \mathrm{~N} 3 \mathrm{~F} 1 \mathrm{~S} 1+$ $\mathrm{H} 6 \mathrm{~N} 3 \mathrm{~F} 1 \mathrm{~S} 1+\mathrm{G} 1 \mathrm{FS}+\mathrm{G} 2 \mathrm{FS}+\mathrm{H} 6 \mathrm{~N} 4 \mathrm{~F} 1 \mathrm{~S} 1+\mathrm{G} 1 \mathrm{FNS}+\mathrm{G} 2 \mathrm{FNS}$ $+\mathrm{H} 6 \mathrm{~N} 5 \mathrm{~F} 1 \mathrm{~S} 1+\mathrm{H} 4 \mathrm{~N} 3 \mathrm{~S} 1+\mathrm{H} 5 \mathrm{~N} 3 \mathrm{~S} 1+\mathrm{H} 6 \mathrm{~N} 3 \mathrm{~S} 1+\mathrm{G} 1 \mathrm{~S}+\mathrm{G} 2 \mathrm{~S}$ $+\mathrm{H} 6 \mathrm{~N} 4 \mathrm{~S} 1+\mathrm{G} 1 \mathrm{NS}+\mathrm{G} 2 \mathrm{NS}+\mathrm{H} 6 \mathrm{~N} 5 \mathrm{~S} 1) * 0.5+\mathrm{G} 2 \mathrm{FS} 2+\mathrm{G} 2$ $\mathrm{FNS} 2+\mathrm{G} 2 \mathrm{~S} 2+\mathrm{G} 2 \mathrm{NS} 2]$, hybrid-types $(\mathrm{H} 5 \mathrm{~N} 3 \mathrm{~F} 1+\mathrm{H} 6 \mathrm{~N} 3 \mathrm{~F} 1$ $+\mathrm{H} 6 \mathrm{~N} 4 \mathrm{~F} 1+\mathrm{H} 6 \mathrm{~N} 5 \mathrm{~F} 1+\mathrm{H} 5 \mathrm{~N} 3 \mathrm{~F} 1 \mathrm{~S} 1+\mathrm{H} 6 \mathrm{~N} 3 \mathrm{~F} 1 \mathrm{~S} 1+\mathrm{H} 6 \mathrm{~N} 4 \mathrm{~F} 1 \mathrm{~S}$ $1+\mathrm{H} 6 \mathrm{~N} 5 \mathrm{~F} 1 \mathrm{~S} 1+\mathrm{H} 5 \mathrm{~N} 3+\mathrm{H} 6 \mathrm{~N} 3+\mathrm{H} 6 \mathrm{~N} 4+\mathrm{H} 6 \mathrm{~N} 5+\mathrm{H} 5 \mathrm{~N} 3 \mathrm{~S} 1$ $+\mathrm{H} 6 \mathrm{~N} 3 \mathrm{~S} 1+\mathrm{H} 6 \mathrm{~N} 4 \mathrm{~S} 1+\mathrm{H} 6 \mathrm{~N} 5 \mathrm{~S} 1)$, and high-mannose (H5N2 + $\mathrm{H} 6 \mathrm{~N} 2+\mathrm{H} 7 \mathrm{~N} 2+\mathrm{H} 8 \mathrm{~N} 2+\mathrm{H} 9 \mathrm{~N} 2)$. For some of the minor hybridtype glycans, it could not be determined conclusively whether a galactose or a bisecting $N$-acetylglucosamine was present, so an educated guess was made based on structural knowledge (for instance, since the hybrid glycan H6N4F1 is elevated in GNTIIIco-transfected HEK cell-derived IgG samples, it is likely to be a bisected species rather than triantennary).

\section{High-Performance Liquid Chromatography (HPLC)}

Protein A purified IgG was analyzed for monomeric and dimeric IgG on a Superdex 200 10/300 gel filtration column $(30 \mathrm{~cm}, 24 \mathrm{ml}$, 17-15175-01, GE Healthcare, Little Chalfont, United Kingdom) connected to an Äkta explorer (GE Healthcare) HPLC system at RT with a flow rate of $0.5 \mathrm{ml} / \mathrm{min}$ and PBS as running buffer. Elution profiles were obtained by recording the absorbance at $215 \mathrm{~nm}$.

\section{Human Fc $\gamma R$ Constructs}

Human Fc $\gamma$ R constructs [Fc $\gamma$ RIa (HIS tag), Fc $\gamma$ RIa (131His, Biotinylated, and 131Arg, Biotinylated), Fc $\gamma$ RIIb (Biotinylated), FcyRIIIa (158Phe, Biotinylated, and 158Val, Biotinylated) and FcyRIIIb (NA2, HIS tag)] for surface plasmon resonance (SPR) analysis were obtained from Sino biological (Beijing, China). To further include all human Fc $\gamma$ Rs, a fusion Fc-FcyR construct composed of the extracellular domain of the FcyRIIIb in both allotypes followed by a Fc domain was created. To create the fusion Fc-FcyRIIIb constructs the amino acid code of the extracellular domain of either Fc $\gamma$ RIIIb of NA1 allotype or Fc $\gamma$ RIIIb NA2 allotype (37) (NCBI reference sequence NP_000561.3), and IgG2 Fc domain, composed of a human IgA1a hinge, human IgG2 Fc CH2 and $\mathrm{CH} 3$ domains including mutations deleting the Fc-glycan (N297A) and introducing a C-terminal biotinylation tag (BirA) were reverse translated and codon optimized at Geneart. DNA was ordered (Integrated DNA technologies, Coralville, IA, USA) and cloned into pcDNA3.1 (Invitrogen, Carlsbad, CA, USA) expression vector using flanking HindIII and EcoRV restriction sites. A model of the construct and sequences are displayed in Figures S7A,B in Supplementary Material. The construct was produced and purified as described previously (31). After purification the protein was site-specifically biotinylated on the BirA tag using BirA enzyme as described by Rodenko et al. (38). For biotinylation of $1 \mu \mathrm{M}$ Fc $\gamma \mathrm{R}$ protein $0.00657 \mu \mathrm{M}$ BirA ligase was used. After biotinylation overnight at $25^{\circ} \mathrm{C}$, the Fc $\gamma \mathrm{R}$ sample was buffer-exchanged and subsequently concentrated in PBS pH 7.4 using Amicon Ultra centrifugal filter units (MWCO $30 \mathrm{kDa}$ ) (Merck, Millipore, Darmstadt, Germany). The quality of the
Fc-Fusion receptors was confirmed by comparing the binding of normally glycosylated IgG1 to the acquired his-tagged receptor (Sino-biological) and in-house made Fc-Fusion of the same allotype (NA2) (Figures S7C,D in Supplementary Material).

\section{Surface Plasmon Resonance}

Surface plasmon resonance measurement were performed as described by Dekkers et al. (39). All biotinylated Fc $\gamma$ R were spotted using a Continuous Flow Microspotter (Wasatch Microfluidics, Salt Lake City, UT, USA) onto a single SensEye G-streptavidin sensor (Ssens, Enschede, Netherlands) allowing for binding affinity measurements of each antibody to all FcyR simultaneously on the IBIS MX96 (IBIS Technologies, Enschede, Netherlands) as described by de Lau et al. (40). The biotinylated Fc $\gamma$ Rs were spotted in threefold dilutions, ranging from 100 to

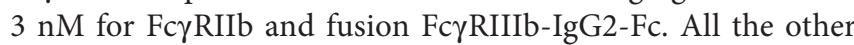
Fc $\gamma$ Rs were spotted in threefold dilutions, ranging from 30 to $1 \mathrm{nM}$ in PBS 0.0075\% Tween-80 (Amresco), pH 7.4. The IgGs were then injected over the IBIS at 1.5 dilution series starting at $5.9 \mathrm{nM}$ until $506.25 \mathrm{nM}$ or $0.9 \mathrm{nM}$ until 2,000 nM, when necessary, in PBS in $0.075 \%$ Tween-80. For Fc $\gamma$ RI affinity and Fc $\gamma$ RIIIb control measurements, his-tagged Fc $\gamma$ RI or Fc $\gamma$ RIIIb was used. Biotinylated anti-His-tagged antibody (Genscript Piscataway, NJ, USA) was spotted in threefold dilutions, ranging from 30 to $1 \mathrm{nM}$. Before every IgG injection, $50 \mathrm{nM}$ his-tagged Fc $\gamma \mathrm{R}$ was injected. The IgGs were then injected over the IBIS at threefold dilution series starting at $0.41 \mathrm{nM}$ until $100 \mathrm{nM}$ for Fc $\gamma$ RI and $94 \mathrm{nM}$ until 3,000 nM for FcyRIIIb. Regeneration after every sample was carried out with acid buffer $(10 \mathrm{mM}$ Gly-HCl, $\mathrm{pH} 2.4)$. Calculation of the dissociation constant $\left(K_{\mathrm{D}}\right)$ was done using an equilibrium analysis by linear intrapolation to $\operatorname{Rmax}=500$ (41). Analysis and calculation of all binding data were carried out with Scrubber software version 2 (Biologic Software, Campbell, ACT, Australia) and Microsoft Office Excel 2013.

\section{NK Cell-Mediated ADCC}

NK cells were isolated from Ficoll-Plaque ${ }^{\mathrm{TM}}$-Plus (GE Healthcare) gradient obtained PBMCs by a CD56 magneticactivated cell separation isolation kit (Miltenyi Biotec, Leiden, The Netherlands), according to manufacturer's description. $\mathrm{D}+\mathrm{RBCs}$ were isolated and labeled with radioactive chromium $\left(100 \mu \mathrm{Ci}^{51} \mathrm{Cr}\right.$, PerkinElmer, Waltham, MA, USA) at $10^{9} \mathrm{cells} / \mathrm{ml}$. An amount of $10^{5}$ erythrocytes were incubated with NK cells for $2 \mathrm{~h}$ at $37^{\circ} \mathrm{C}$ in a 2:1 ratio in Iscove's modified dulbecco's medium (IMDM, Gibco, Thermo Fisher Scientific) supplemented with $10 \%$ fetal calf serum (FCS, Bodinco, Alkmaar, The Netherlands) and anti-D IgG1-glycoforms at a total volume of $100 \mu \mathrm{l}$. To determine $100 \%$ lysis, $2.5 \%$ saponine (Fluka, Sigma Aldrich) was added to RBC in control wells and spontaneous lysis (sp) was determined by incubation of RBC without NK cells. Supernatants were collected and released ${ }^{51} \mathrm{Cr}$ was quantified in a Packard Cobra II Auto-Gamma Counter Model D5005 (PerkinElmer). Percentage cytotoxicity was determined by the following formula: $\operatorname{ADCC}(\%)=\frac{\text { counts sample }- \text { counts } \mathrm{sp}}{\text { counts } 100 \%-\text { counts } \mathrm{sp}} \times 100$, each value consisted of at least three individual sample wells. 


\section{Complement Deposition ELISA}

A 2.4-mM 2,4,6-trinitrobenzenesulfonic acid (TNBS) (SigmaAldrich) solution was added to $20 \mathrm{mg}$ human serum albumin (HSA) diluted to $20 \mathrm{mg} / \mathrm{ml}$ (Sanquin, Amsterdam, The Netherlands) in 0.2 $\mathrm{M} \mathrm{NA}_{2} \mathrm{HPO}_{4}$ (Merck, Millipore) and incubated $30 \mathrm{~min}$ at RT. To remove unbound TNBS, the solution was dialyzed $(1: 2,000)$ using a dialysis cassette (Thermo Fisher Scientific Slide-A-Lyzer G2 cassette, 10K MWCO) for $1.5 \mathrm{~h}$ at RT against PBS and additionally overnight at $4^{\circ} \mathrm{C}$ to obtain HSA-TNP.

To coat, maxisorp plates (Thermo Scientific, Nunc flat-bottom 96-well plate) were incubated $\mathrm{o} / \mathrm{n}$ at RT with $20 \mu \mathrm{g} / \mathrm{ml} \mathrm{HSA-TNP}$ in PBS. The plates were washed $5 \times$ with PBS $+0.1 \%$ tween- 20 (Sigma-Aldrich) (wash buffer) using an ELISA washer (Biotek, 405 LSRS). All following washing steps were done similarly. The IgG samples were diluted in $100 \mu \mathrm{lBS} / \mathrm{plx}$ [PBS $+0.1 \%$ poloxamer (Sigma-Aldrich, poloxamer 407)] per well and incubated for $1.5 \mathrm{~h}$ at RT. The plates were washed and incubated with $100 \mu \mathrm{l}$ $1: 35$ serum pool in $\mathrm{VB}^{+/+} / \mathrm{plx}$ \{veronalbuffer [3 $\mathrm{mM}$ Barbital (Sigma-Aldrich), $1.8 \mathrm{mM}$ Sodium-Barbital (Sigma Aldrich), $0.146 \mathrm{M} \mathrm{NaCl}$ (Fagron, Capelle aan den Ijssel, The Netherlands), $\mathrm{pH} 7.4]+10 \mathrm{mM} \mathrm{CaCl}_{2}$ (Merck) + $2 \mathrm{mM} \mathrm{MgCl}_{2}$ (Merck) + 0.1\% poloxamer\} for $1 \mathrm{~h}$ at RT. When C1q was blocked, 10 min prior to addition of serum to the ELISA plate, anti-C1q-85 blocking antibody (42) was added to the $\mathrm{VB}^{+/+} / \mathrm{plx}+1: 35$ serum solution in a 1:2 molar ratio of C1q:anti-C1q-85 with final concentration of $8.57 \mu \mathrm{g} / \mathrm{ml}$ anti-C1q-85. The plates were washed and $100 \mu \mathrm{l}$ with either $2 \mu \mathrm{g} / \mathrm{ml}$ biotinylated anti-C1q-2 (42), $0.5 \mu \mathrm{g} / \mathrm{ml}$ biotinylated anti-C4-10 (43), $0.6 \mu \mathrm{g} / \mathrm{ml}$ biotinylated anti-C3-19 (44), or $1 \mu \mathrm{g} / \mathrm{ml}$ HRP labeled anti-human IgG (Sanquin, Peliclass) in PBS/plx was added to respectively detect C1q, C4b, $\mathrm{C} 3 \mathrm{~b}$, or IgG deposition and incubated for $1 \mathrm{~h}$ at RT. The plates were washed, C1q, C4b, and C3 plates were incubated with $100 \mu \mathrm{l}$ $0.2 \mu \mathrm{g} / \mathrm{ml}$ strep-poly HRP (Sanquin, Peliclass) (C1q) or $0.25 \mu \mathrm{g} /$ $\mathrm{ml}$ strep-HRP (Sigma-Aldrich) (C4b and C3b) in PBS/plx for $1 \mathrm{~h}$ at RT. The plates were washed and developed for 5-10 min using $100 \mu \mathrm{l}$ TMB mix composed of $0.11 \mathrm{M} \mathrm{NaAc}$ (pH 5.5) (Merck),

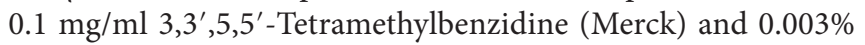
$\mathrm{H}_{2} \mathrm{O}_{2}$ (Merck) and the reaction was stopped with the addition of $100 \mu \mathrm{l} 2 \mathrm{M} \mathrm{H}_{2} \mathrm{SO}_{4}$ (Merck). The optical density (OD) was measured at A450 nm using a plate reader (Biotek, Synergy 2, Winooski, VT, USA).

The results were analyzed with a parallel line assay in Microsoft Office Excel (45). We assessed the potency of the glycoforms relative to a standard, an independently titrated unmodified IgG1; these values were expressed as percentages relative to the unmodified glycoform.

\section{Complement-Mediated Lysis}

Fifty microliters of washed, packed, $\mathrm{D}^{+} \mathrm{RBC}$ obtained from heparinized blood were mixed with $350 \mu \mathrm{l} 0.313 \mathrm{mM}$ TNBS in $0.15 \mathrm{M}$ $\mathrm{Na}_{2} \mathrm{HPO}_{4}, \mathrm{pH} 8.8$ and incubated for $10 \mathrm{~min}$ at RT. TNPylated RBCs were centrifuged for $2 \mathrm{~min}$ at $350 \times g$ and washed two times with PBS. RBC were resuspended into $\mathrm{VBG}^{+/+}\left[\mathrm{VB}^{+/+}+0.05 \%\right.$ w/v gelatin (Sigma-Aldrich)]. Anti-TNP IgG1 was serially diluted in $\mathrm{VBG}^{-1-}(3 \mathrm{mM}$ Barbital, $1.8 \mathrm{mM}$ Sodium-Barbital, $0.146 \mathrm{M} \mathrm{NaCl}, \mathrm{pH} 7.4,0.05 \% \mathrm{w} / \mathrm{v}$ gelatin). In round bottom plates to a final volume of $100 \mu$ we combined the diluted IgG1, $10 \%$ serum, $\sim 4.5 \times 10^{6} \mathrm{RBC}$, and a glass bead ( $2 \mathrm{~mm}$, Merck) to ensure mixing of the solution during incubation (1:1 final ratio

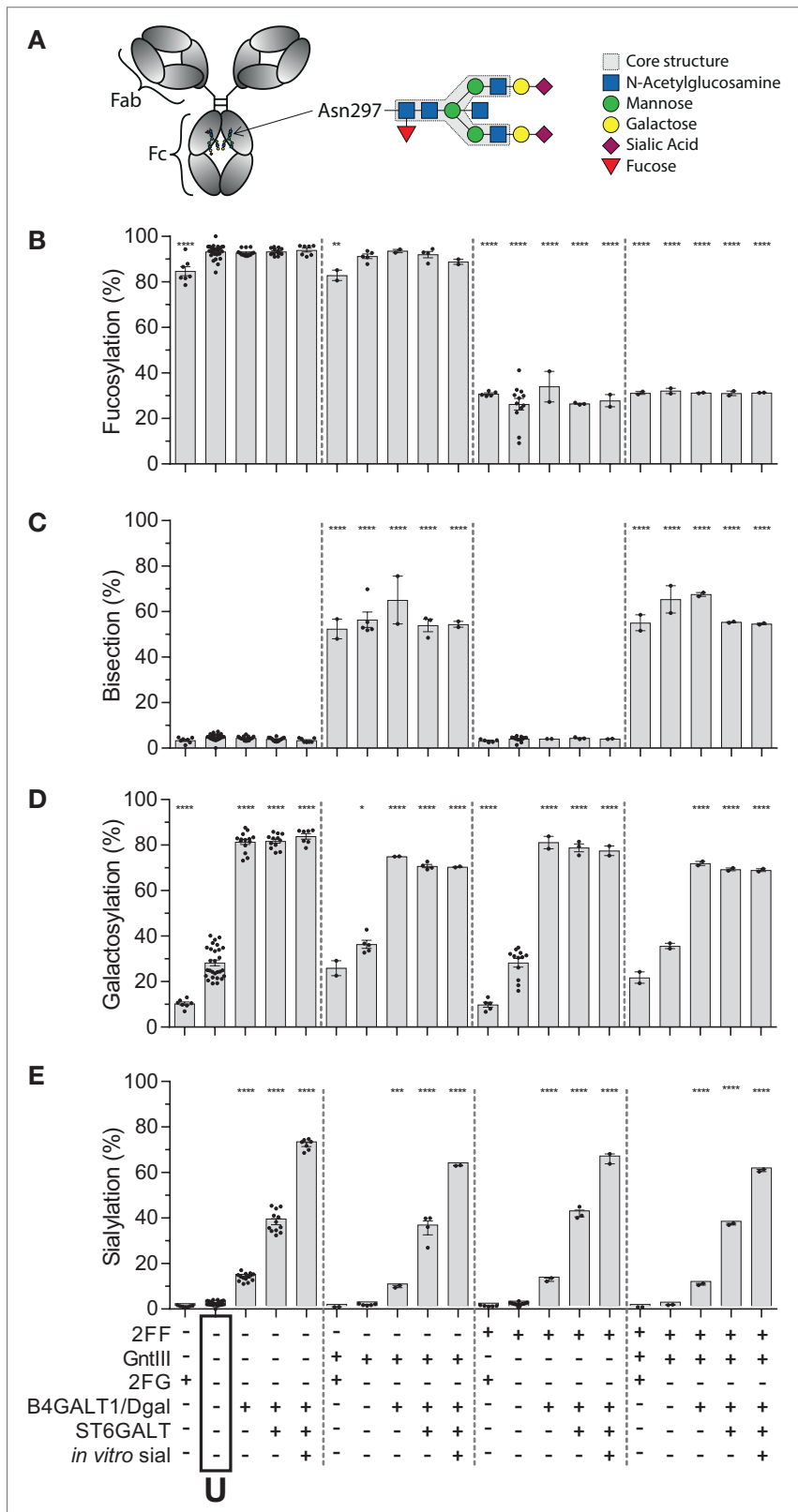

FIGURE 1 | Recapitulation of 20 different immunoglobulin G (lgG) glycoforms by glyco-engineering. (A) Model of lgG with glycan at position N297 in the FC domain and composition of the glycan. (B-E) Degree of derived glycan traits as reached by the different glyco-engineering tools: 2FF, $0.4 \mathrm{mM}$ 2-deoxyfluoro-L-fucose; Gntlll, 1\% Gntlll co-transfection; 2FG, 1 mM 2-deoxy-fluoroD-galactose; B4galT1/Dgal, 1\% B4GALT1 co-transfection and $5 \mathrm{mM}$ D-galactose; ST6GALT, 2.5\% ST6GALT co-transfection, in vitro sial, treatment of IgG with recombinant ST6GALT and CMP-NANA substrate. The data represent the mean and SEM of at least two combined independent experiments; ${ }^{*},{ }^{* \star},{ }^{* \star *}$, and ${ }^{* * * *}$ denote a statistical significance of $p \leq 0.05$, $p \leq 0.01, p \leq 0.001$, and $p \leq 0.0001$, respectively, as tested by one-way ANOVA against unmodified IgG1, using Dunnett's multiple comparisons test. $\mathrm{U}$ : unmodified glycoform. 


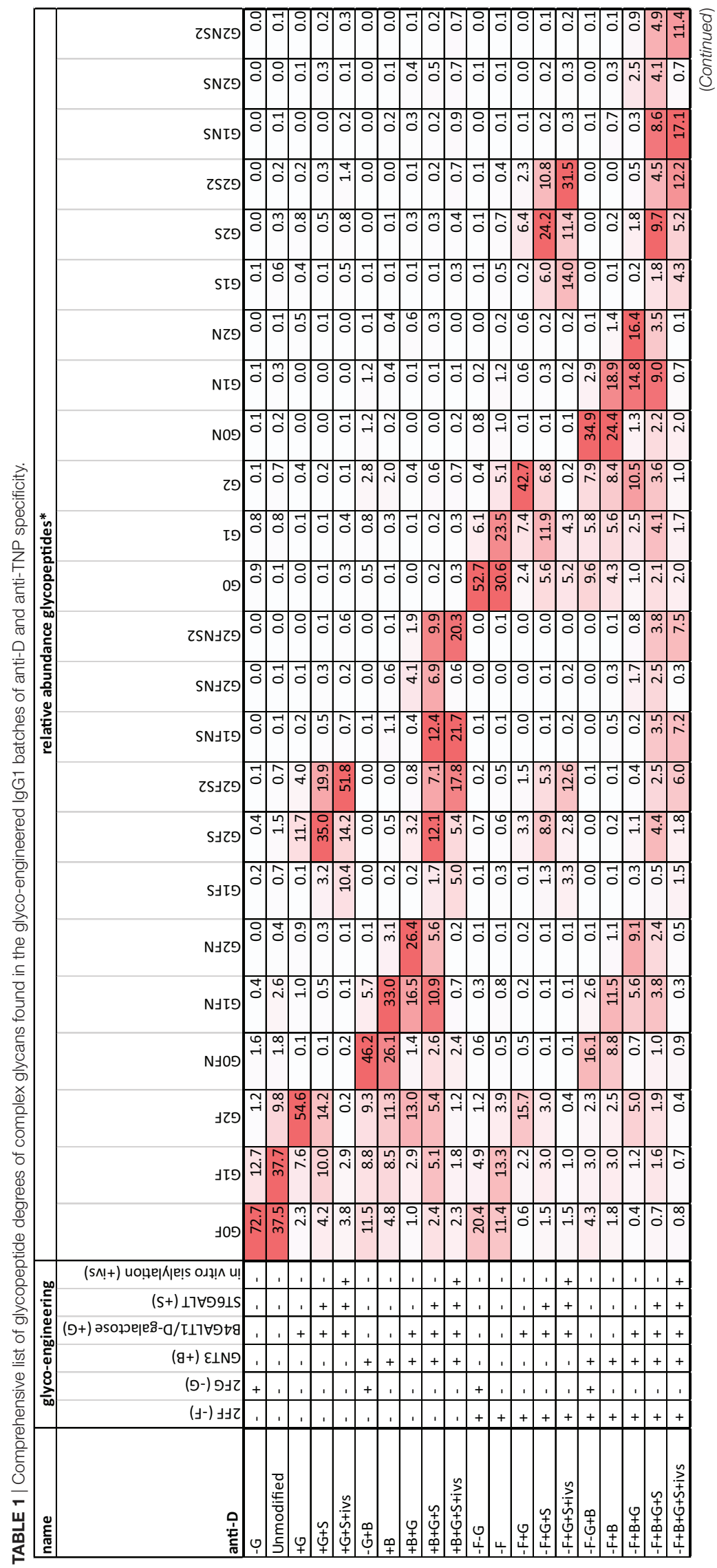



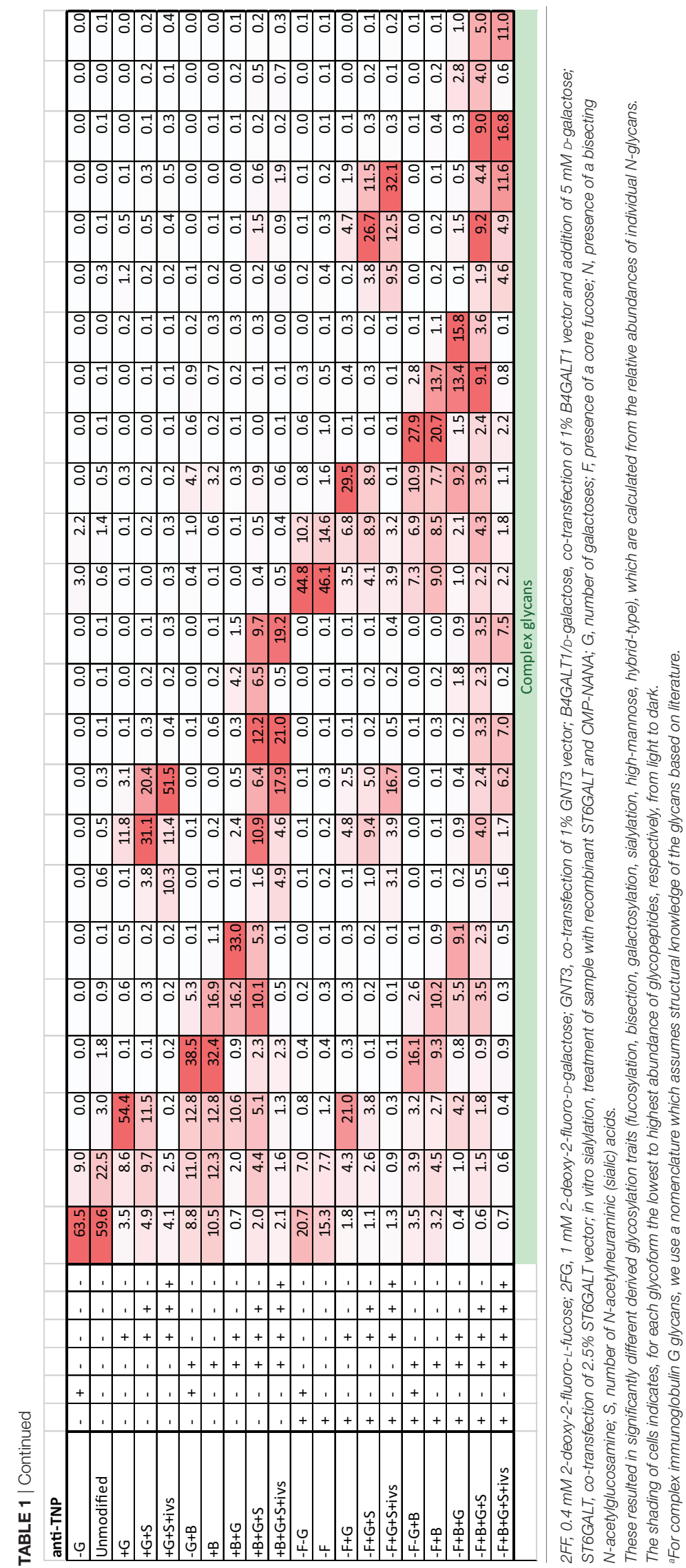
$\left.\mathrm{VBG}^{-/-}: \mathrm{VBG}^{+/+}\right)$. This amount of $\mathrm{RBC}$ was taken to ensure the $100 \%$ absorbance between 1.8 and 2.2 delta $(\Delta)$ A $412-\mathrm{A} 690 \mathrm{~nm}$. The plates were incubated for $90 \mathrm{~min}$ at $37^{\circ} \mathrm{C}$ while shaking at $150 \mathrm{rpm}$ (Orbital incubator S150, $16 \mathrm{~mm}$ shaking diameter). After incubation, $1.25 \% \mathrm{w} / \mathrm{v}$ saponine was supplemented to the $100 \%$ control wells, $100 \mu \mathrm{VBG}^{-1-}$ was added to all wells and the plates were centrifuged for $2 \mathrm{~min}$ at $350 \times \mathrm{g}$. Subsequently, $150 \mu \mathrm{l}$ of supernatant was transferred into a separate plate and OD was measured at $\Delta \mathrm{A} 412-\mathrm{A} 690 \mathrm{~nm}$ using a plate reader. The percentage of lysed cells was calculated as follows: Lysis $(\%)=\frac{\text { OD sample-OD spontaneous }}{\text { OD } 100 \% \text {-OD spontaneous }} \times 100$. In GraphPad Prism, we calculated the half maximal effective concentration $\left(\mathrm{EC}_{50}\right)$ for each replicate of the different glycoforms using a non-linear fit for normalized response with a variable slope and combined these to an average $\mathrm{EC}_{50}$.

\section{Statistical Analysis}

Statistical analyses were performed using GraphPad Prism version 6.00 for Windows (GraphPad Software, La Jolla, CA, USA). The level of significance was set at $p<0.05$ using twotailed tests.

\section{RESULTS}

\section{Recapitulation of All 20 Major Different Glycoforms Found in Human Plasma}

Human IgG1, produced in HEK cells, shows complex-type bi-antennary glycans similar to IgG from normal human plasma (Figure 1A) $(31,46)$. More specifically, without any modification ("Unmodified," box labeled " $U$ " in the $x$-axis legend, Figures 1B-E) HEK-derived IgG1 N-glycans feature high fucosylation, low bisection, intermediate-level galactosylation, and low sialylation (Figures 1B-E). We previously developed six glyco-engineering tools which can be implemented upon protein production, as we recently described (31). These were aimed to decrease fucosylation, increase bisection, decrease or increase galactosylation, or increase sialylation. In the present study, these tools were combined and used in all possible combinations during the transient transfection in HEK cells, which resulted in the anticipated glycosylation changes and allowed us to produce the 20 major glycoforms present in human serum. Only minor unanticipated effects (Figures 1B-E), were observed. A slight increase in galactosylation upon overexpression of beta $1,4-\mathrm{N}$-acetylglucosaminyltransferase III (GntIII) to increase bisection (e.g., 28 to $36 \%$ upon GntIII expression)-but this was only observed in samples with low starting-levels of galactosylation (Figures 1C,D). Some of the tools caused a minor increase $(<21 \%)$ in high-mannose or hybrid glycan species (Figure S1 and Table S1 in Supplementary Material) (31). Using the glyco-engineering tools the most extreme levels were reached for fucose and galactose (Figures 1B,D), bisection was increased up to $60 \%$, and sialylation never reached over half of what was possible by the underlying galactose $(\sim 40 \%)$. The level of sialylation was, therefore, further increased using in vitro sialylation as described before (up to $70 \%$ ) (Figure 1E; Table 1)
$(31,47,48)$. All in all, this resulted in 20 combinations and markedly different glycoforms. All 20 glycoforms were produced as two panels of IgG1, specific for the RhD (anti-D) antigen or 2,4,6-trinitrophenyl hapten (anti-TNP) (34), with both panels showing highly comparable glycosylation patterns depending of the glyco-engineering tools applied (Table 1; Table S1 in Supplementary Material). To avoid any possible confounding effects of Fab glycosylation on IgG function, we used anti-D and anti-TNP with variable domains sequences devoid of $\mathrm{N}$-linked glycosylation sites.

\section{Binding of IgG Glycome to Human Fc $\gamma R$}

We next used the IBIS MX96 biosensor system, as described in Dekkers et al. (39), capable of analyzing the binding of up to 48 different receptor ligand interactions in parallel by SPR, to probe the affinity of all IgG1-glycoforms to all human FcyRs and their allotypes affecting IgG binding (Table S2 in Supplementary Material) (49). The antibodies used for these experiments (anti-D) showed no signs of dimers or multimers (Figure S2 in Supplementary Material). The binding affinities of unmodified IgG1 to the different receptors resembled those reported earlier (Table 2) (49). We considered significant changes in the apparent $K_{\mathrm{D}}$ of more than twofold from unmodified IgG to be potentially meaningful changes and within the scope of the SPR method, using a simplified 1:1 Langmuir model that does not fully represent the actual interaction which is more complicated (39). No significant effects of glycan changes above twofold were seen on the binding to Fc $\gamma$ RIa, Fc $\gamma$ RIIa (neither the H131- or the R131-allotype), or FcyRIIb/c (Figures 2A-D). However, marked changes were seen for all FcyRIII-isoforms. Reduction of fucose resulted in enhanced binding to all FcyRIII species by approximately 10 - to 20 -fold depending on the type- and allotype (Figures $2 \mathbf{E}-\mathbf{H})$, as reported $(4,5)$. Importantly, addition of galactose consistently enhanced binding of hypo-fucosylated IgG1 for all Fc $\gamma$ RIIIa allotypes, doubling the effect of hypofucosylation alone (Figures 2E,F). This effect was also seen for allotypes of FcyRIIIb, but less strong and only for IgG1 that was bisected in addition to hypo-fucosylated (Figures 2G,H). Further sialylation of low-fucosylated galactosylated IgG1 had little additional effect on the binding to FcyRIII, except for hypo-fucosylated and bisected IgG1 for both allotypes of Fc $\gamma$ RIIIa and Fc $\gamma$ RIIIb NA2, where sialylation cause a significant decrease in binding. Taken together, glycan changes

TABLE 2 | Affinity of unmodified lgG1 (U) to the different FcyRs.

\begin{tabular}{|c|c|c|}
\hline & Mean affinity & SEM \\
\hline $\mathrm{F}_{\mathrm{c} \gamma \mathrm{RI}}$ & $3.0 \times 10^{-9}$ & $\pm 8.7 \times 10^{-10}$ \\
\hline $\mathrm{F}_{\mathrm{C} \gamma \mathrm{R}} \mathrm{Il}^{131 \mathrm{H}}$ & $3.8 \times 10^{-7}$ & $\pm 1.3 \times 10^{-8}$ \\
\hline $\mathrm{F}_{\mathrm{c} \gamma \mathrm{R}} \mathrm{Rl}^{131 \mathrm{R}}$ & $4.8 \times 10^{-7}$ & $\pm 2.8 \times 10^{-8}$ \\
\hline FcyRllb & $2.7 \times 10^{-6}$ & $\pm 1.1 \times 10^{-7}$ \\
\hline$F_{c} \gamma R_{1 l l a}{ }^{158 F}$ & $1.3 \times 10^{-6}$ & $\pm 9.5 \times 10^{-8}$ \\
\hline FcyRIIIIa158v & $2.4 \times 10^{-7}$ & $\pm 1.0 \times 10^{-8}$ \\
\hline FcyRIIIb NA1 & $3.2 \times 10^{-6}$ & $\pm 4.7 \times 10^{-7}$ \\
\hline FcyRIIIb NA2 & $2.8 \times 10^{-6}$ & $\pm 1.0 \times 10^{-7}$ \\
\hline
\end{tabular}

Affinity in $K_{D}$, as measured by SPR. 
A

Fc $\gamma$ Rla

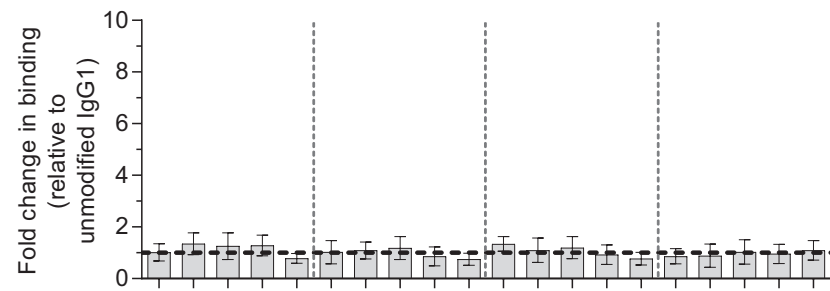

C

Fc $\gamma$ RIla 131R

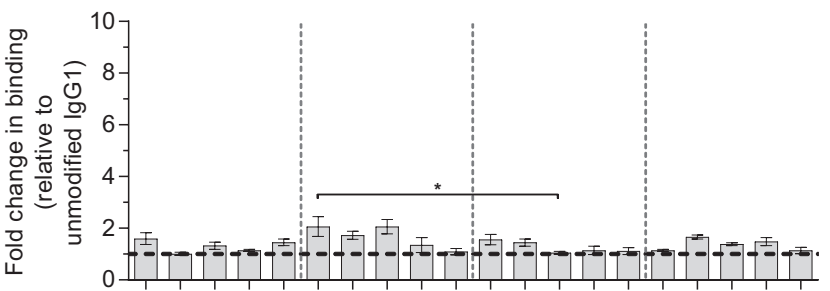

E

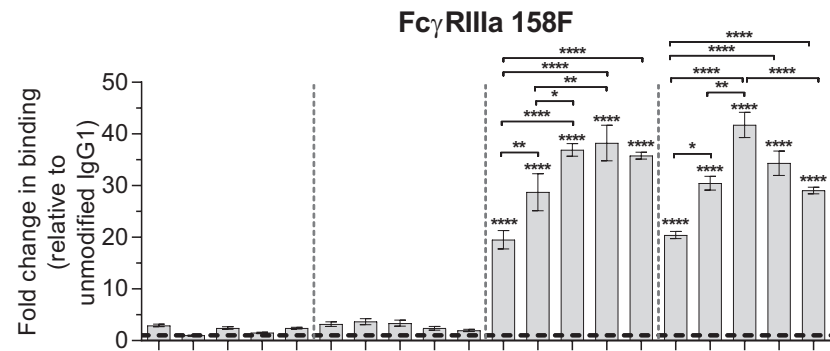

G

Fc-Fc $\gamma$ RIIIb NA1

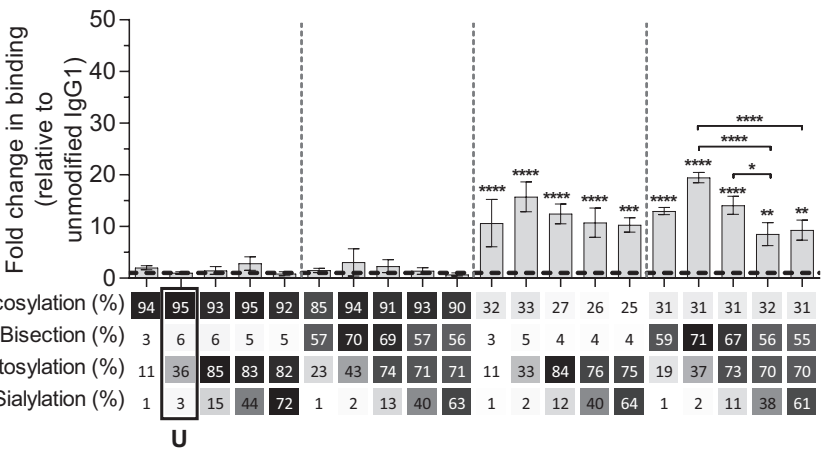

B

Fc $\gamma$ Rlla 131H

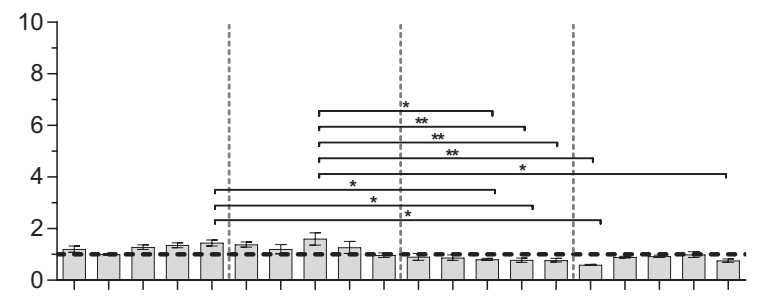

D

Fc $\gamma$ RIlb/c

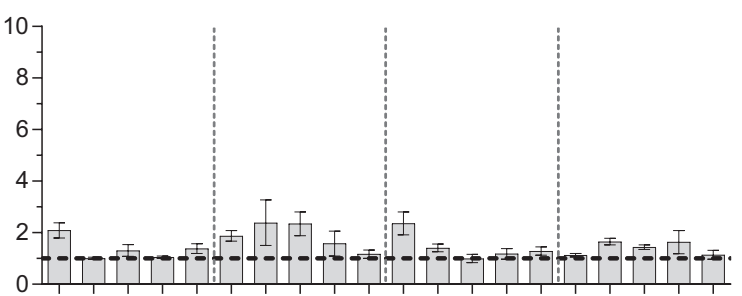

F

Fc $\gamma$ RIIIa 158V

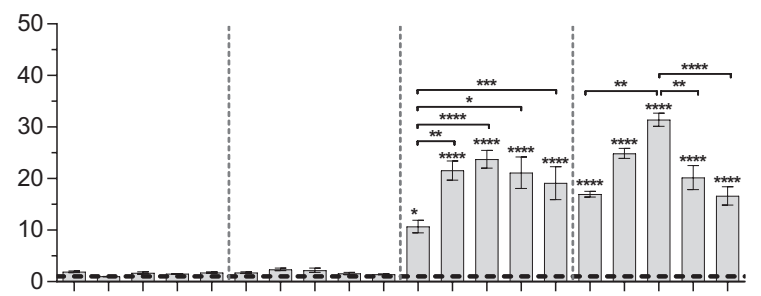

H

Fc-Fc $\gamma$ RIIIb NA2

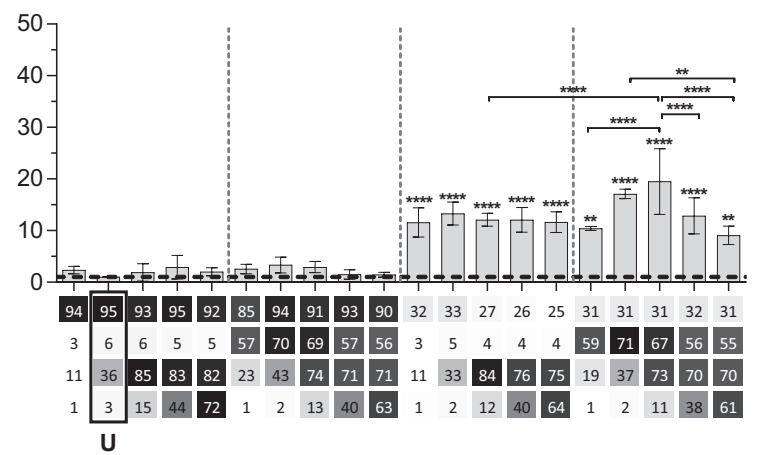

FIGURE 2 | Binding of immunoglobulin G (IgG) glycoforms to human FcyR. Binding of IgG glycoforms to the human FcyR family as determined by surface plasmon resonance, displayed as relative binding compared to unmodified IgG1 (U), (A) FcyRl, (B) FcyRlla 131H, (C) FcyRlla 131R, (D) FcyRllb/c, (E) FcyRllla V158, (F) FcyRllla F158, (G) FcyRlllb NA1, and (H) FcyRlllb NA2. $x$-Axis legend describes the percentage of each derived glycan trait indicated and by grayscale, from light to dark. The data represent the mean and SEM of at least two combined independent experiments; ${ }^{*},{ }^{\star \star},{ }^{\star \star \star}$, and ${ }^{* \star \star \star}$ (above each column as tested against unmodified, or as indicated, for FcyRllls comparing each set of five glycoforms defined by the vertical dotted lines, based on fucose and bisection levels) denote a statistical significance of $p \leq 0.05, p \leq 0.01, p \leq 0.001$, and $p \leq 0.0001$, respectively, as tested by one-way ANOVA using Tukey's multiple comparisons test. U: unmodified glycoform.

in the IgG-Fc only affect binding to FcyRIIIa and FcyRIIIb, with a major effect of hypo-fucosylation increasing binding to FcyRIIIa/b that was boosted by galactosylation. Bisection only appeared to indirectly affect binding when occurring in conjunction with sialylation, causing a slight decreased binding to FcyRIIIa/b to otherwise hypo-fucosylated and galactosylated IgG.

\section{Fc $\gamma$ RIIla-Mediated ADCC Is Steered by Fucosylation and Galactosylation}

We next tested the efficacy of these anti-D IgG1 antibodies to mediate ADCC against RBC. Curiously, no NK cell-mediated induction of ADCC was seen with any fucosylated IgG1 at any concentration tested (Figures 3A,B; Figure S3 in Supplementary 


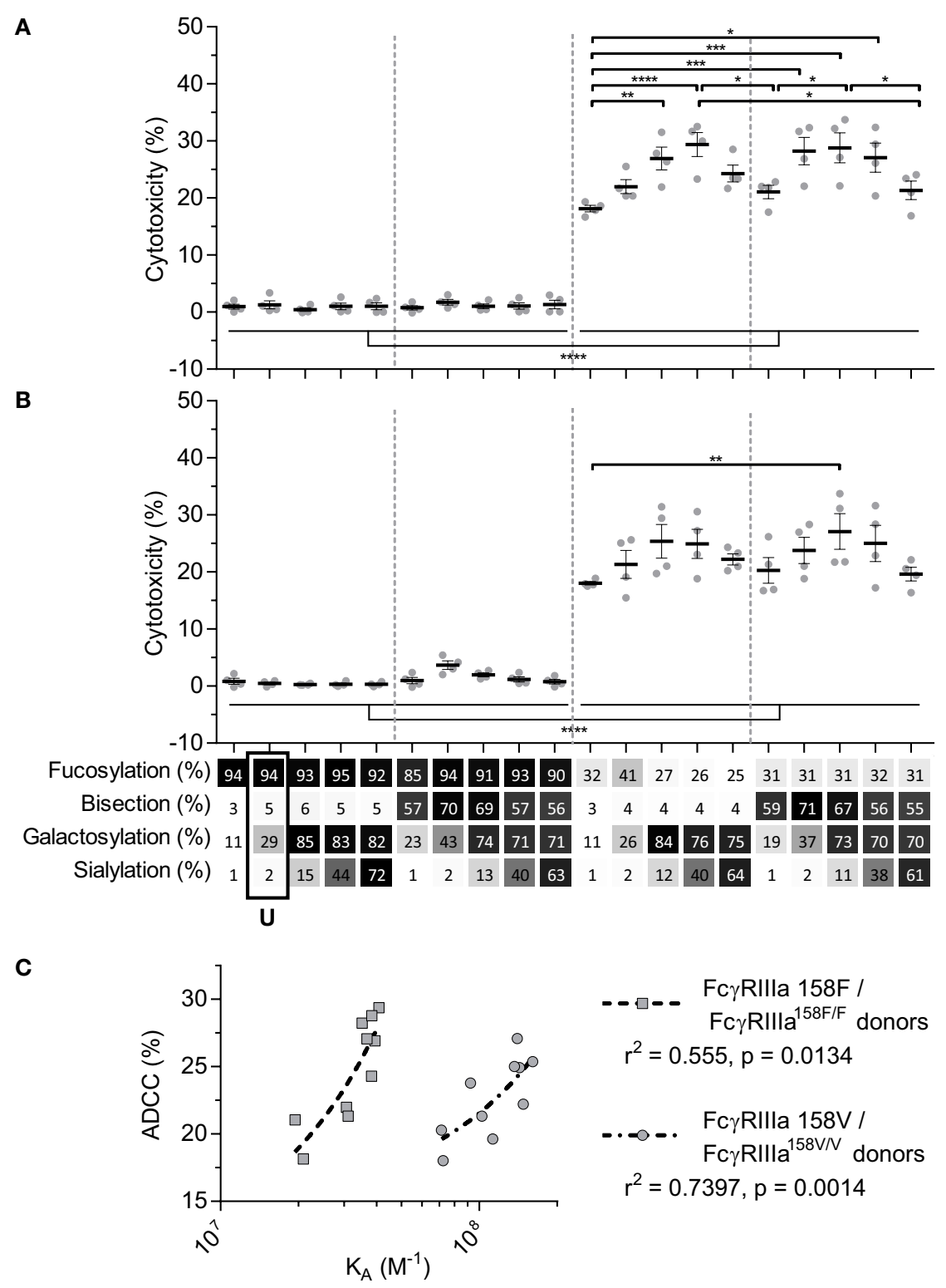

FIGURE 3 | NK cell-mediated antibody-dependent cellular cytotoxicity (ADCC) of anti-D glycoform opsonized red blood cell. ADCC mediated by NK cells from

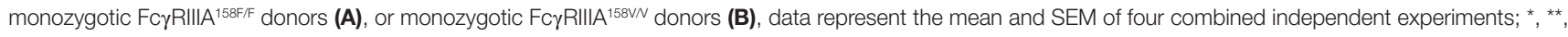
${ }^{\star * \star}$, and ${ }^{* \star *}$ denote a statistical significance of $p \leq 0.05, p \leq 0.01, p \leq 0.001$, and $p \leq 0.0001$, respectively, as tested by one-way ANOVA using Tukey's multiple comparisons test. $x$-Axis legend describes the percentage of each derived glycan trait indicated and by grayscale, from light to dark. (C) Correlation between $K_{\mathrm{A}}$ of FcyRIIla F158 or Fc $\gamma R$ IIlla V158 binding of hypo-fucosylated glycoforms and ADCC activity of FcyRIIIA ${ }^{158 F / F}$ or FcyRIIIA ${ }^{158 V N}$ donors, respectively. $r^{2}$ and $p$ value shown where obtained using a two-tailed Pearson's correlation. U: unmodified glycoform.

Material). Only hypo-fucosylated IgG1 induced ADCC in variable degrees depending on the glycosylation (Figures 3A,B). The observed level of ADCC were in line with the binding results obtained by SPR for each of the Fc $\gamma$ RIIIa allotypes (Figure 3C), confirming the essential role of both hypo-fucosylation and elevated galactosylation for increased FcyRIIIa-binding and effector functions. Again, sialic acid had a minor but significant negative effect, especially for the bisected, hypo-fucosylated, and galactosylated IgG1 (Figures 3A,B). Remarkably, the wellknown allotypic differences in affinity were confirmed by our
SPR experiments, but not by the functional NK cell-mediated ADCC.

\section{Galactosylation and Sialylation Direct Complement Binding and Activation}

We then tested the effect of IgG-Fc glycosylation on $\mathrm{C} 1 \mathrm{q}$ binding and subsequent complement activation, using the anti-TNP panel of IgG1 antibodies as anti-D does not fix complement. The efficiency of C1q binding to TNP-lated human 
serum albumin (TNP-HSA) and subsequent C4b deposition was titrated by serial dilution (Figure S4 in Supplementary Material). All glycovariants of anti-TNP bound TNP-HSA equally well (Figure S4A in Supplementary Material), but C1q binding and $\mathrm{C} 4 \mathrm{~b}$ deposition differed profoundly for the different glycoforms (Figure S4B in Supplementary Material). The relative $\mathrm{C} 1 \mathrm{q}$ binding and $\mathrm{C} 4 \mathrm{~b}$ deposition were then calculated (Figures 4A,B, respectively). Both data sets suggested that elevated galactosylation and sialylation positively influenced complement activity. This activity was fully depended on the classical pathway with no influence of the mannan-binding lectin- or the alternative pathway, as $\mathrm{C} 4 \mathrm{~b}$ and $\mathrm{C} 3 \mathrm{~b}$ deposition, were completely blocked by an anti-C1q blocking antibody (Figure S5 in Supplementary Material). We then determined if this also translates into more efficient complement-dependent cytotoxicity (CDC) by analyzing complement-dependent lysis of TNP-labeled RBC (Figure 4C; Figure S6 in Supplementary Material). The level of $\mathrm{C} 1 \mathrm{q}$ binding of each glycoform correlated well with the $\mathrm{C} 4 \mathrm{~b}$ deposition (Figure 5A) and with the obtained $\mathrm{EC}_{50}$ of CDC (Figure 5B). The level of galactosylation of each

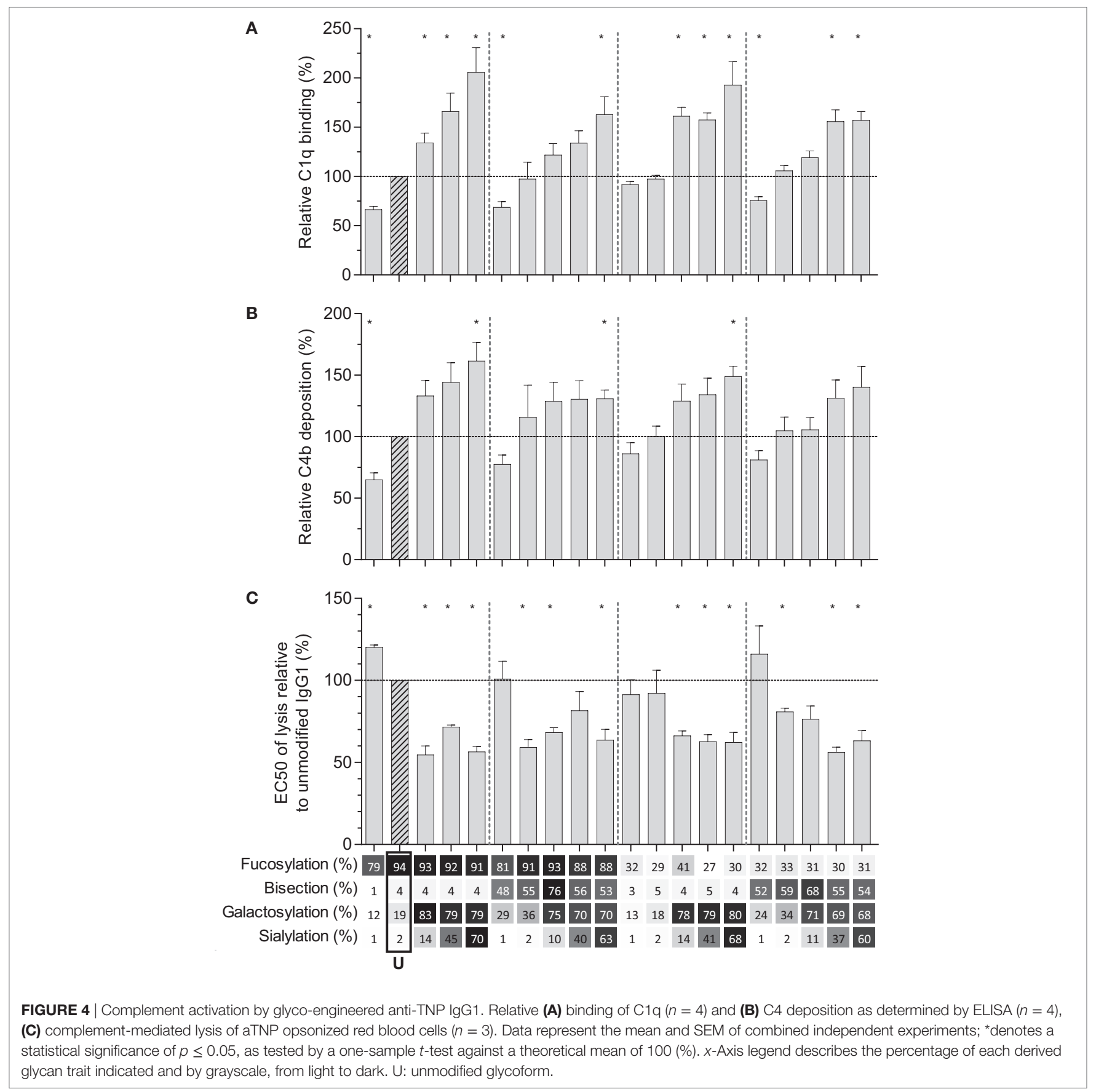




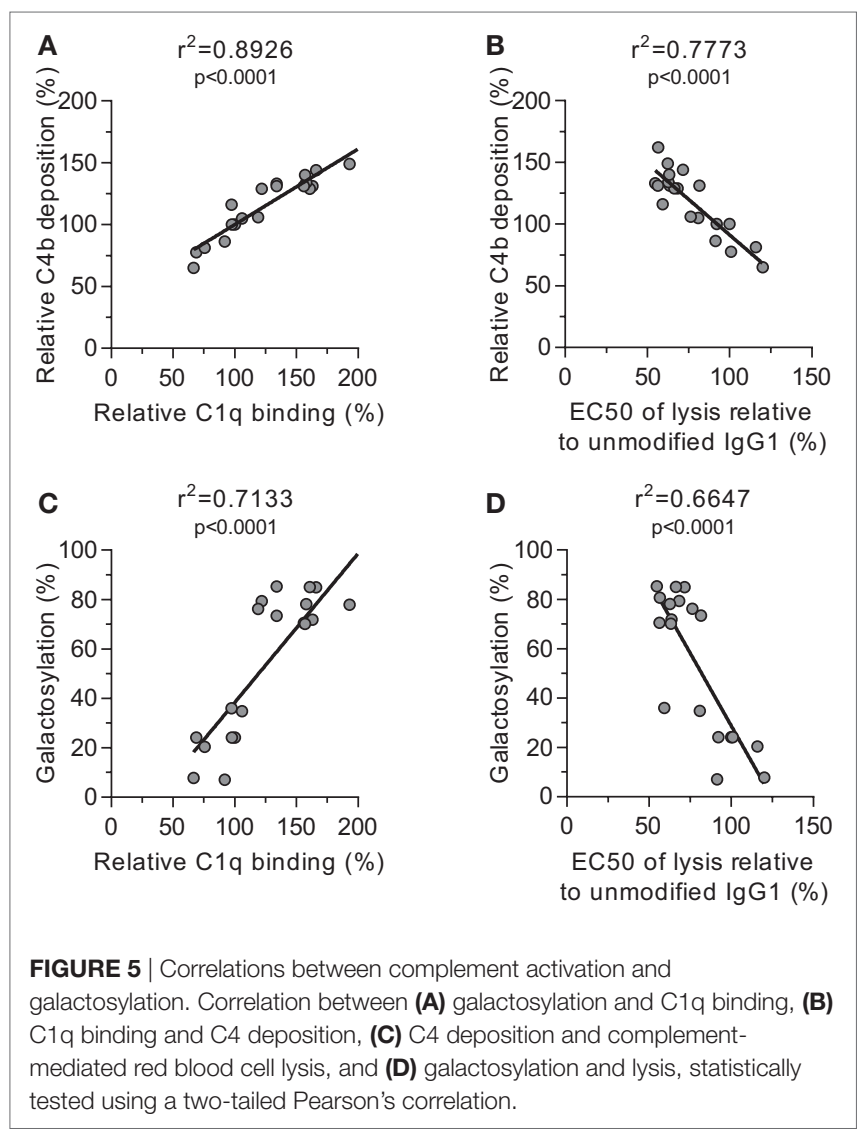

glycoform also showed a direct relationship with the efficacy of $\mathrm{C} 1 \mathrm{q}$ binding, and $\mathrm{EC}_{50}$ (Figures $5 \mathrm{C}, \mathrm{D}$ ). In conclusion, the degree of galactosylation, but also sialylation of the IgG1-Fc $\mathrm{N}$-glycan directly steers the antibody's efficacy to stimulate complement deposition and CDC.

\section{DISCUSSION}

We have previously created an orthogonal set of glyco-engineering tools (31) which we now combined to create 20 glycovariants of human IgG1, representing natural variants found in human plasma IgG, including extreme glycoforms found for examples in patients with FNAIT and $\operatorname{HDFN}(17,18,21,22)$. These variants were investigated for their functional capacity to engage and activate Fc $\gamma \mathrm{R}$ and complement.

Of the FcyRs, we only observed an effect of glycosylation on binding to the FcyRIII-family of receptors, both FcyRIIIa and FcyRIIIb and their allotypes, which confirms and expands recent studies using a limited set of glycovariants presented here $(24,30)$. Increased FcyRIII binding seems to be a general phenomenon for all IgG subclasses upon afucosylation $(50,51)$. The positive binding effects were primarily caused by the lack of fucose, which was further strengthened by additional galactose. A similar effect has been observed for neutralizing anti-HIV antibody 2 G12 produced in modified plant cells which showed better Fc $\gamma$ RIIIa binding and antibody-dependent (NK) cell-mediated viral inhibition (52).

The enhanced binding of galactosylated and afucosylated IgG was slightly weakened by addition of sialic acid, but only if a bisecting GlcNAc was present. A similar negative effect of sialylation has previously been observed for mouse Fc $\gamma \mathrm{R}$ by Ravetch and colleagues (53). Importantly, we showed that the enhanced FcyRIII-binding effects are directly translated into increased FcyR-mediated cellular functions. We tested this using NK cell-mediated ADCC, as NK cells are the only cell type that only express FcyRIIIa. Curiously, we observed no ADCC at all for fucosylated IgG, even at high concentrations of IgG1. Thus, ADCC activity was only observed with afucosylated IgG1. Although somewhat surprising, this phenomenon has been observed previously for anti-Rhesus-mediated ADCC (54), but also for Rituximab-mediated B cell killing (27). This suggests that the enhanced affinity afucosylation of IgG has on FcyRIIIa binding is required to cross a signaling threshold of Fc $\gamma$ RIIIa on NK cells required for killing.

The second surprise was that no significant difference was observed between ADCC-capacity of NK cells from donors homozygous for one of the two FcyRIIIa-V/F158 allotypes, of which the V158 allele is known to have higher affinity for IgG (also confirmed here to be $\sim 2-5 \times$ ) (49). In vitro, this has been found result in stronger functional efficacy for the V158-variant (55-57). In vivo, conflicting reports have showed that individuals homozygous either the V158 or the F158 allotype show stronger cellular clearance (58-61). It should be noted that most of these studies were performed before the knowledge of FcyRIII gene being influenced by copy number variation (61). We also now know that NK cells can also express Fc $\gamma$ RIIc or Fc $\gamma$ RIIb in some individuals. Both these variations affect the functionality of this receptor $(32,62,63)$. In this study, we eliminated both these variables by selecting donors with two copies of FcyRIIIa and without FcyRIIc-ORF, possibly explaining these discrepancies, and perhaps suggesting that the twofold to fivefold difference in affinity of IgG1 allotype is not enough to cause functional differences.

Importantly, the observed changes in FcyRIIIa-binding due to glycosylation reliably translated into functional NK cellmediated ADCC lysis of RBC. For FcyRIIIa and FcyRIIIb it was known that absence of IgG-Fc core-fucosylation increases the affinity of interaction due to a glycan-glycan interaction between the Fc glycan and the N162-glycan uniquely found in the FcyRIII family (11). Our approach to combine this with multiple end glycan editing shows an additional layer of complexity exerted by the galactose and sialic acid. The reasons for this added effect of galactose is unknown but may very well be related to the subtle effects on quaternary structure of the $\mathrm{Fc}$-domain $(64,65)$ but may also be related to differential interaction of the Fc-glycan with the N162-glycan found in FcyRIII (11).

The possible effect of the Fc-glycans on complement activity, has until now remained enigmatic. It has been proposed for a long time that agalactosylated IgG activates complement more efficiently through the lectin pathway (MBL) (25). To our knowledge 


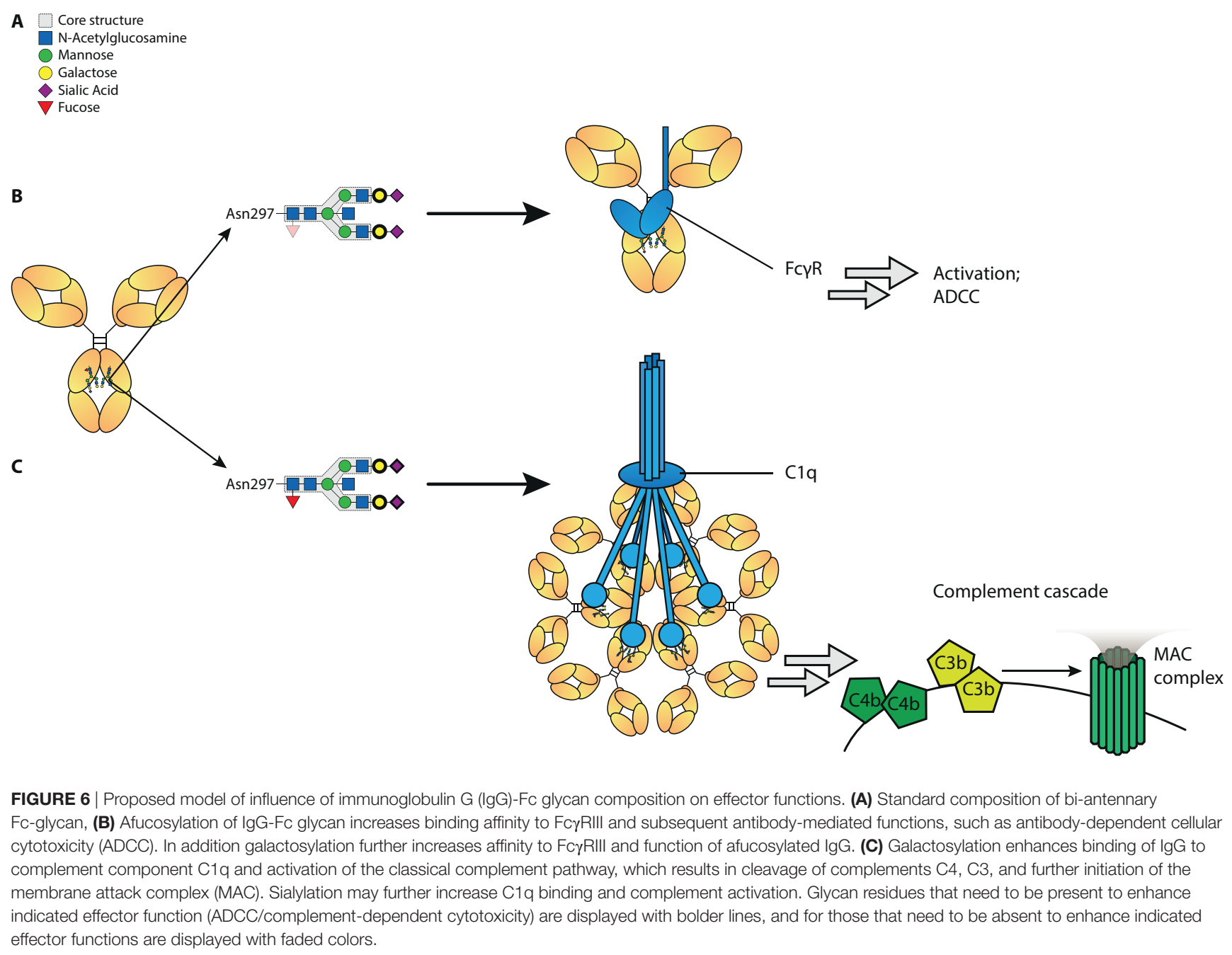

these results have never been confirmed. On the contrary, we saw enhanced complement activity of all glycovariants with elevated galactose, and no evidence of MBL being activated by any of our glycoforms. These results confirm recent work also suggesting galactosylation of IgG1 to positively influence $\mathrm{Clq}$ binding and CDC $(26,66)$. In addition, our results clearly rule out fucosylation or bisection having an effect on complement activation, and we now show that sialylation increases the C1q-binding of galactosylated IgG. This effect of sialylation was observed on all different glycan backbones (e.g., with or without fucose, with or without bisection) which is highly suggestive that this is no artifactual finding. This is in contrast with the previously mentioned study showing that additional sialylation decreases C1q binding (26). Activation of complement is dependent on spatial arrangement of the IgG on the cell surface (67) which is likely to differ considerably between each monoclonal antibody and target, and may possibly explain the discrepancies found between our two studies. This view is supported by our observations that sialylation had limited if any effect on IgG-mediated CDC using RBC as targets, while binding to $\mathrm{Clq}$ of anti-TNP antibodies was enhanced by sialylated IgG on solid surfaces.
Low galactosylation level in total IgG generally correlates with disease severity of several autoimmune diseases, such as rheumatoid arthritis and multiple sclerosis $(13,14)$. While this may seem at odds with our observations at first glance, with high galactosylated IgG having elevated complement and Fc $\gamma \mathrm{R}$ activities, both notions are in agreement if the balance between total- and antigen-specific glycosylation is taken into account. In this way, low potential for FcyR- and C1q binding for total IgG (e.g., low galactosylation), creates a pro-inflammatory environment in which clinical manifestations can take hold as this lowers the threshold for pathogenic antibodies. Antigen-specific IgG can also potentially have different glycosylation features than total $\operatorname{IgG}$ as we have shown before $(17,18,21,22)$, and if these are more pro-inflammatory than that of total IgG, this can theoretically lead to enhanced immune activation and clinical symptoms. The knowledge obtained in the current research provides a roadmap to decipher the meaning of glycan profiles in these diseases settings.

In summary, we show here that a set of glyco-engineering techniques we recently developed (31) can be combined to quickly generate any desired IgG glycoforms to test the effect 
on functional capacity. Using two sets of monoclonal antibodies we generated the most extreme 20 different glycoforms possible, and examined their effect on binding to FcyR and complement, as well as their functional capacity to trigger cytotoxicity. These revealed first that the normal glycosylation changes seen in human IgG1 do not affect any other Fc $\gamma$ R than Fc $\gamma$ RIIIa and Fc $\gamma$ RIIIb. Second, hypo-fucosylation and galactosylation increase binding to both human FcyRIII-variants, with a minor negative effect of sialic acid and bisecting GlcNAc. In addition, galactosylation is the primary glycan adduct that enhances C1q-binding and all downstream complement activities, including CDC. This is summarized in Figure 6. Collectively, this indicates that afucosylated and hyper-galactosylated IgG1 antibodies have both improved ADCC and complement-mediated activities, including complement opsonization and CDC. These properties can now be systematically implemented in new therapeutic antibodies for enhanced effector functions. Even as important, this also allows us to decipher the clinical potency of antibodies in immune responses that have tendency to have altered fucosylation and/ or galactosylation $(17,18,21,22)$.

\section{ETHICS STATEMENT}

Peripheral blood from anonymous, healthy volunteers was obtained with informed, written consent of all subjects, in accordance with Dutch regulations. This study was approved by the Sanquin Ethical Advisory Board in accordance with the Declaration of Helsinki.

\section{REFERENCES}

1. Bruhns P, Jönsson F. Mouse and human FcR effector functions. Immunol Rev (2015) 268:25-51. doi:10.1111/imr.12350

2. Weiner LM, Surana R, Wang S. Monoclonal antibodies: versatile platforms for cancer immunotherapy. Nat Rev Immunol (2010) 10:317-27. doi:10.1038/ nri2744

3. Weiner GJ. Building better monoclonal antibody-based therapeutics. Nat Rev Cancer (2015) 15:361-70. doi:10.1038/nrc3930

4. Shields RL, Lai J, Keck R, O’Connell LY, Hong K, Meng YG, et al. Lack of fucose on human IgG1 N-linked oligosaccharide improves binding to human Fcgamma RIII and antibody-dependent cellular toxicity. J Biol Chem (2002) 277:26733-40. doi:10.1074/jbc.M202069200

5. Shinkawa T, Nakamura K, Yamane N, Shoji-Hosaka E, Kanda Y, Sakurada M, et al. The absence of fucose but not the presence of galactose or bisecting $\mathrm{N}$-acetylglucosamine of human IgG1 complex-type oligosaccharides shows the critical role of enhancing antibody-dependent cellular cytotoxicity. J Biol Chem (2003) 278:3466-73. doi:10.1074/jbc.M210665200

6. Beck A, Reichert JM. Marketing approval of mogamulizumab: a triumph for glyco-engineering. MAbs (2012) 4:419-25. doi:10.4161/mabs.20996

7. Subedi GP, Hanson QM, Barb AW. Restricted motion of the conserved immunoglobulin G1 N-glycan is essential for efficient Fc $\gamma$ RIIIa binding. Structure (2014) 22:1478-88. doi:10.1016/j.str.2014.08.002

8. Jefferis R. Recombinant antibody therapeutics: the impact of glycosylation on mechanisms of action. Trends Pharmacol Sci (2009) 30:356-62. doi:10.1016/j. tips.2009.04.007

9. Caaveiro JMM, Kiyoshi M, Tsumoto K. Structural analysis of Fc/FcyR complexes: a blueprint for antibody design. Immunol Rev (2015) 268:201-21. doi:10.1111/imr.12365

10. Sondermann P, Huber R, Oosthuizen V, Jacob U. The 3.2-A crystal structure of the human IgG1 Fc fragment-Fc gammaRIII complex. Nature (2000) 406:267-73. doi:10.1038/35018508

\section{AUTHOR CONTRIBUTIONS}

GD, TK, DW, TR, MW, and GV designed the research. GD, AB, DW, TR, MW, and GV designed the experiments. GD, LT, RP, $\mathrm{AB}, \mathrm{MdB}, \mathrm{CK}, \mathrm{SL}-\mathrm{T}, \mathrm{RV}$, and YM performed the experiments. GD, RP, AB, MdB, CK, TR, TK, MW, and GV analyzed data, GD and GV wrote the manuscript. All authors contributed to and approved the final manuscript.

\section{ACKNOWLEDGMENTS}

The authors would like to thank Ninotska Derksen, Pleuni De Heer-Ooijevaar, Prof. Dr. Rob Aalberse, and Sanne van de Bovenkamp for practical help and Prof. Dr. Ellen van der Schoot, Prof. Dr. Rob Aalberse, Sanne van de Bovenkamp, Dr. Juan J. Garcia-Vallejo, Willem Falkenburg, and Christine Bruggeman for fruitful discussions, and Prof. Dr. Ellen van der Schoot for critically reading the manuscript.

\section{FUNDING}

This study was supported by Sanquin Product and Process Development Plasma Products, 12-001, Gestur Vidarsson.

\section{SUPPLEMENTARY MATERIAL}

The Supplementary Material for this article can be found online at http://journal.frontiersin.org/article/10.3389/fimmu.2017.00877/ full\#supplementary-material.

11. Ferrara C, Grau S, Jäger C, Sondermann P, Brünker P, Waldhauer I, et al. Unique carbohydrate-carbohydrate interactions are required for high affinity binding between FcgammaRIII and antibodies lacking core fucose. Proc Natl Acad Sci U S A (2011) 108:12669-74. doi:10.1073/pnas.1108455108

12. Baković MP, Selman MHJ, Hoffmann M, Rudan I, Campbell H, Deelder AM, et al. High-throughput IgG Fc N-glycosylation profiling by mass spectrometry of glycopeptides. J Proteome Res (2013) 12:821-31. doi:10.1021/pr300887z

13. Bondt A, Selman MHJ, Deelder AM, Hazes JMW, Willemsen SP, Wuhrer M, et al. Association between galactosylation of immunoglobulin $\mathrm{G}$ and improvement of rheumatoid arthritis during pregnancy is independent of sialylation. J Proteome Res (2013) 12:4522-31. doi:10.1021/pr400589m

14. Wuhrer M, Selman MHJ, McDonnell LA, Kümpfel T, Derfuss T, Khademi M, et al. Pro-inflammatory pattern of IgG1 Fc glycosylation in multiple sclerosis cerebrospinal fluid. J Neuroinflammation (2015) 12:235. doi:10.1186/s12974-015-0450-1

15. Chen G, Wang Y, Qiu L, Qin X, Liu H, Wang X, et al. Human IgGFc-glycosylation profiling reveals associations with age, sex, female sex hormones and thyroid cancer. J Proteomics (2012) 75:2824-34. doi:10.1016/j.jprot.2012.02.001

16. Wuhrer M, Porcelijn L, Kapur R, Koeleman CAM, Deelder A, de Haas M, et al. Regulated glycosylation patterns of IgG during alloimmune responses against human platelet antigens. J Proteome Res (2009) 8:450-6. doi:10.1021/ pr800651j

17. Kapur R, Della Valle L, Sonneveld M, Hipgrave Ederveen A, Visser R, Ligthart $P$, et al. Low anti-RhD IgG-Fc-fucosylation in pregnancy: a new variable predicting severity in haemolytic disease of the fetus and newborn. Br J Haematol (2014) 166:936-45. doi:10.1111/bjh.12965

18. Sonneveld ME, Natunen S, Sainio S, Koeleman CAM, Holst S, Dekkers G, et al. Glycosylation pattern of anti-platelet IgG is stable during pregnancy and predicts clinical outcome in alloimmune thrombocytopenia. Br J Haematol (2016) 174:310-20. doi:10.1111/bjh.14053

19. Ackerman ME, Crispin M, Yu X, Baruah K, Boesch AW, Harvey DJ, et al. Natural variation in Fc glycosylation of HIV-specific antibodies 
impacts antiviral activity. JClin Invest (2013) 123:2183-92. doi:10.1172/ JCI65708

20. Wang TT, Sewatanon J, Memoli MJ, Wrammert J, Bournazos S, Bhaumik SK, et al. IgG antibodies to dengue enhanced for Fc $\gamma$ RIIIA binding determine disease severity. Science (2017) 355:395-8. doi:10.1126/science.aai8128

21. Kapur R, Kustiawan I, Vestrheim A, Koeleman CA, Visser R, Einarsdottir HK, et al. A prominent lack of IgG1-Fc fucosylation of platelet alloantibodies in pregnancy. Blood (2014) 123:471-80. doi:10.1182/blood-2013-09-527978

22. Sonneveld ME, Koelewijn J, de Haas M, Admiraal J, Plomp R, Koeleman CAM, et al. Antigen specificity determines anti-red blood cell IgG-Fc alloantibody glycosylation and thereby severity of haemolytic disease of the fetus and newborn. Br J Haematol (2017) 176:651-60. doi:10.1111/bjh.14438

23. Kapur R, Heitink-poll KMJ, Porcelijn L, Bentlage AEH, Bruin MC, Visser $\mathrm{R}$, et al. C-reactive protein enhances IgG-mediated phagocyte responses and thrombocytopenia. Blood (2015) 125:1793-803. doi:10.1182/ blood-2014-05-579110

24. Thomann M, Schlothauer T, Dashivets T, Malik S, Avenal C, Bulau P, et al. In vitro glycoengineering of $\operatorname{IgG1}$ and its effect on $\mathrm{Fc}$ receptor binding and ADCC activity. PLoS One (2015) 10:e0134949. doi:10.1371/journal. pone. 0134949

25. Malhotra R, Wormald MR, Rudd PM, Fischer PB, Dwek RA, Sim RB. Glycosylation changes of IgG associated with rheumatoid arthritis can activate complement via the mannose-binding protein. Nat Med (1995) 1:237-43. doi:10.1038/nm0395-237

26. Quast I, Keller CW, Maurer MA, Giddens JP, Tackenberg B, Wang LX, et al. Sialylation of IgG Fc domain impairs complement-dependent cytotoxicity. J Clin Invest (2015) 125:4160-70. doi:10.1172/JCI82695

27. LiH, Sethuraman N, Stadheim TA, Zha D, Prinz B, Ballew N, et al. Optimization of humanized IgGs in glycoengineered Pichia pastoris. Nat Biotechnol (2006) 24:210-5. doi:10.1038/nbt1178

28. Yang Z, Wang S, Halim A, Schulz MA, Frodin M, Rahman SH, et al. Engineered CHO cells for production of diverse, homogeneous glycoproteins. Nat Biotechnol (2015) 33:2014-7. doi:10.1038/nbt.3280

29. Meuris L, Santens F, Elson G, Festjens N, Boone M, Dos Santos A, et al. GlycoDelete engineering of mammalian cells simplifies N-glycosylation of recombinant proteins. Nat Biotechnol (2014) 32:485-9. doi:10.1038/ nbt. 2885

30. Subedi GP, Barb AW. The immunoglobulin G1 N-glycan composition affects binding to each low affinity Fc $\gamma$ receptor. MAbs (2016) 8:1512-24. doi:10.10 80/19420862.2016.1218586

31. Dekkers G, Plomp R, Koeleman CAM, Visser R, von Horsten HH, Sandig V, et al. Multi-level glyco-engineering techniques to generate IgG with defined Fc-glycans. Sci Rep (2016) 6:36964. doi:10.1038/srep36964

32. van der Heijden J, Breunis WB, Geissler J, de Boer M, van den Berg TK, Kuijpers TW. Phenotypic variation in IgG receptors by nonclassical FCGR2C alleles. J Immunol (2012) 188:1318-24. doi:10.4049/jimmunol.1003945

33. Della Valle L, Dohmen SE, Verhagen OJHM, Berkowska MA, Vidarsson G, Ellen van der Schoot C. The majority of human memory B cells recognizing $\mathrm{RhD}$ and tetanus resides in IgM+ B cells. J Immunol (2014) 193:1071-9. doi:10.4049/jimmunol.1400706

34. Kruijsen D, Einarsdottir HK, Schijf MA, Coenjaerts FE, van der Schoot EC, Vidarsson G, et al. Intranasal administration of antibody-bound respiratory syncytial virus particles efficiently primes virus-specific immune responses in mice. J Virol (2013) 87:7550-7. doi:10.1128/JVI.00493-13

35. Chambers MC, Maclean B, Burke R, Amodei D, Ruderman DL, Neumann S, et al. A cross-platform toolkit for mass spectrometry and proteomics. Nat Biotechnol (2012) 30:918-20. doi:10.1038/nbt.2377

36. Plomp R, Dekkers G, Rombouts Y, Visser R, Koeleman CAM, Kammeijer GSM, et al. Hinge-region O-glycosylation of human immunoglobulin G3 (IgG3). Mol Cell Proteomics (2015) 14:1373-84. doi:10.1074/mcp.M114.047381

37. Ory PA, Clark MR, Kwoh EE, Clarkson SB, Goldstein IM. Sequences of complementary DNAs that encode the NA1 and NA2 forms of Fc receptor III on human neutrophils. J Clin Invest (1989) 84:1688-91. doi:10.1172/ JCI1 14350

38. Rodenko B, Toebes M, Hadrup SR, van Esch WJE, Molenaar AM, Schumacher TNM, et al. Generation of peptide-MHC class I complexes through UV-mediated ligand exchange. Nat Protoc (2006) 1:1120-32. doi:10.1038/nprot.2006.121
39. Dekkers G, Bentlage AEH, Stegmann TC, Howie HL, Lissenberg-Thunnissen S, Zimring J, et al. Affinity of human IgG subclasses to mouse Fc gamma receptors. MAbs (2017) 1-7. doi:10.1080/19420862.2017.1323159

40. de Lau W, Barker N, Low TY, Koo B-K, Li VSW, Teunissen H, et al. Lgr5 homologues associate with Wnt receptors and mediate R-spondin signalling. Nature (2011) 476:293-7. doi:10.1038/nature10337

41. Schasfoort RBM, Andree KC, van der Velde N, van der Kooi A, Stojanović I, Terstappen LWMM. Interpolation method for accurate affinity ranking of arrayed ligand-analyte interactions. Anal Biochem (2016) 500:21-3. doi:10.1016/ j.ab.2016.01.023

42. McGrath FDG, Brouwer MC, Arlaud GJ, Daha MR, Hack CE, Roos A. Evidence that complement protein $\mathrm{Clq}$ interacts with C-reactive protein through its globular head region. J Immunol (2006) 176:2950-7. doi:10.4049/ jimmunol.176.5.2950

43. Leito JTD, Ligtenberg AJM, van Houdt M, van den Berg TK, Wouters D. The bacteria binding glycoprotein salivary agglutinin (SAG/gp340) activates complement via the lectin pathway. Mol Immunol (2011) 49:185-90. doi:10.1016/j. molimm.2011.08.010

44. Hack CE, Paardekooper J, Smeenk RJ, Abbink J, Eerenberg AJ, Nuijens JH. Disruption of the internal thioester bond in the third component of complement (C3) results in the exposure of neodeterminants also present on activation products of $\mathrm{C} 3$. An analysis with monoclonal antibodies. J Immunol (1988) 141:1602-9.

45. Armitage P, Colton T. In: Armitage P, Colton Chichester T, editors. Encyclopedia of Biostatistics. UK: John Wiley \& Sons, Ltd (2005).

46. Fokkink WJR, Falck D, Santbergen TCM, Huizinga R, Wuhrer M, Jacobs BC. Comparison of $\mathrm{Fc} \mathrm{N}$-glycosylation of pharmaceutical products of intravenous immunoglobulin G. PLoS One (2015) 10:e0139828. doi:10.1371/journal. pone. 0139828

47. Barb AW, Brady EK, Prestegard JH. Branch-specific sialylation of IgG-Fc glycans by ST6Gal-I. Biochemistry (2009) 48:9705-7. doi:10.1021/ bi901430h

48. Washburn N, Schwab I, Ortiz D, Bhatnagar N, Lansing JC, Medeiros A, et al. Controlled tetra-Fc sialylation of IVIg results in a drug candidate with consistent enhanced anti-inflammatory activity. Proc Natl Acad Sci U S A (2015) 112:201422481. doi:10.1073/pnas.1422481112

49. Bruhns P, Iannascoli B, England P, Mancardi DA, Fernandez N, Jorieux S, et al. Specificity and affinity of human Fcgamma receptors and their polymorphic variants for human IgG subclasses. Blood (2009) 113:3716-25. doi:10.1182/ blood-2008-09-179754

50. Niwa R, Natsume A, Uehara A, Wakitani M, Iida S, Uchida K, et al. IgG subclass-independent improvement of antibody-dependent cellular cytotoxicity by fucose removal from Asn297-linked oligosaccharides. J Immunol Methods (2005) 306:151-60. doi:10.1016/j.jim.2005.08.009

51. Bruggeman CW, Dekkers G, Bentlage AEH, Treffers LW, Nagelkerke SQ, Lissenberg-Thunnissen S, et al. Enhanced effector functions due to antibody defucosylation depend on the effector cell Fcy receptor profile. J Immunol (2017) 199(1):204-11. doi:10.4049/jimmunol.1700116

52. Forthal DN, Gach JS, Landucci G, Jez J, Strasser R, Kunert R, et al. Fc-glycosylation influences $\mathrm{Fc} \gamma$ receptor binding and cell-mediated antiHIV activity of monoclonal antibody 2G12. J Immunol (2010) 185:6876-82. doi:10.4049/jimmunol.1002600

53. Kaneko Y, Nimmerjahn F, Ravetch JV. Anti-inflammatory activity of immunoglobulin G resulting from Fc sialylation. Science (2006) 313:670-3. doi:10.1126/science.1129594

54. Sibéril S, de Romeuf C, Bihoreau N, Fernandez N, Meterreau J-L, Regenman A, et al. Selection of a human anti-RhD monoclonal antibody for therapeutic use: impact of IgG glycosylation on activating and inhibitory Fc gamma R functions. Clin Immunol (2006) 118:170-9. doi:10.1016/j.clim.2005. 10.008

55. López-Albaitero A, Lee SC, Morgan S, Grandis JR, Gooding WE, Ferrone S, et al. Role of polymorphic Fc gamma receptor IIIa and EGFR expression level in cetuximab mediated, NK cell dependent in vitro cytotoxicity of head and neck squamous cell carcinoma cells. Cancer Immunol Immunother (2009) 58:1853-64. doi:10.1007/s00262-009-0697-4

56. Hatjiharissi E, Xu L, Santos DD, Hunter ZR, Ciccarelli BT, Verselis S, et al. Increased natural killer cell expression of CD16, augmented binding and ADCC activity to rituximab among individuals expressing the Fc\{gamma\} 
RIIIa-158 V/V and V/F polymorphism. Blood (2007) 110:2561-4. doi:10.1182/ blood-2007-01-070656

57. Oboshi W, Watanabe T, Matsuyama Y, Kobara A, Yukimasa N, Ueno I, et al. The influence of NK cell-mediated ADCC: structure and expression of the CD16 molecule differ among FcyRIIIa-V158F genotypes in healthy Japanese subjects. Hum Immunol (2016) 77:165-71. doi:10.1016/j. humimm.2015.11.001

58. Stegmann TC, Veldhuisen B, Nagelkerke SQ, Winkelhorst D, Schonewille H, Verduin EP, et al. RhIg-prophylaxis is not influenced by FCGR2/3 polymorphisms involved in red blood cell clearance. Blood (2017) 129:1045-8. doi:10.1182/blood-2016-05-716365

59. Cartron G, Dacheux L, Salles G, Solal-Celigny P, Bardos P, Colombat P, et al. Therapeutic activity of humanized anti-CD20 monoclonal antibody and polymorphism in IgG Fc receptor FcgammaRIIIa gene. Blood (2002) 99:754-8. doi:10.1182/blood.V99.3.754

60. Burkhardt B, Yavuz D, Zimmermann M, Schieferstein J, Kabickova E, Attarbaschi A, et al. Impact of Fc gamma-receptor polymorphisms on the response to rituximab treatment in children and adolescents with mature B cell lymphoma/leukemia. Ann Hematol (2016) 95:1503-12. doi:10.1007/ s00277-016-2731-x

61. Kumpel BM, De Haas M, Koene HR, Van De Winkel JGJ, Goodrick MJ. Clearance of red cells by monoclonal IgG3 anti-D in vivo is affected by the VF polymorphism of Fcgamma RIIIa (CD16). Clin Exp Immunol (2003) 132:81-6. doi:10.1046/j.1365-2249.2003.02119.x

62. Aitman TJ, Dong R, Vyse TJ, Norsworthy PJ, Johnson MD, Smith J, et al. Copy number polymorphism in Fcgr3 predisposes to glomerulonephritis in rats and humans. Nature (2006) 439:851-5. doi:10.1038/nature04489

63. Thabet MM, Huizinga TWJ, Marques RB, Stoeken-Rijsbergen G, Bakker AM, Kurreeman FA, et al. Contribution of Fcgamma receptor IIIA gene 158V/F polymorphism and copy number variation to the risk of ACPA-positive rheumatoid arthritis. Ann Rheum Dis (2009) 68:1775-80. doi:10.1136/ ard.2008.099309

64. Ahmed AA, Giddens J, Pincetic A, Lomino JV, Ravetch JV, Wang L-X, et al. Structural characterization of anti-inflammatory immunoglobulin G Fc proteins. J Mol Biol (2014) 426:3166-79. doi:10.1016/j.jmb.2014.07.006

65. Le NPL, Bowden TA, Struwe WB, Crispin M. Immune recruitment or suppression by glycan engineering of endogenous and therapeutic antibodies. Biochim Biophys Acta (2016) 1860:1655-68. doi:10.1016/j. bbagen.2016.04.016

66. Pace D, Lewis N, Wu T, Gillespie R, Leiske D, Velayudhan J, et al. Characterizing the effect of multiple Fc glycan attributes on the effector functions and FcyRIIIa receptor binding activity of an IgG1 antibody. Biotechnol Prog (2016) 32(5):1181-92. doi:10.1002/btpr.2300

67. DiebolderCA, BeurskensFJ, de JongRN, Koning RI,StrumaneK, LindorferMA, et al. Complement is activated by IgG hexamers assembled at the cell surface. Science (2014) 343:1260-3. doi:10.1126/science.1248943

Conflict of Interest Statement: The authors declare that this study received funding from Sanquin Bloedvoorziening, a not-for-profit organization. The funder was not involved in the study design or collection, analysis, or interpretation of the data.

Copyright $\odot 2017$ Dekkers, Treffers, Plomp, Bentlage, de Boer, Koeleman, LissenbergThunnissen, Visser, Brouwer, Mok, Matlung, van den Berg, van Esch, Kuijpers, Wouters, Rispens, Wuhrer and Vidarsson. This is an open-access article distributed under the terms of the Creative Commons Attribution License (CC BY). The use, distribution or reproduction in other forums is permitted, provided the original author(s) or licensor are credited and that the original publication in this journal is cited, in accordance with accepted academic practice. No use, distribution or reproduction is permitted which does not comply with these terms. 